\title{
Modeling Aggregate Use of IMF Resources-Analytical Approaches and Medium-Term Projections
}

\author{
ATISH GHOSH, MANUELA GORETTI, BIKAS JOSHI, ALUN THOMAS, and \\ JUAN ZALDUENDO*
}

This paper presents two approaches to modeling the use of IMF resources from the General Resources Account in order to gauge whether the recent decline in credit outstanding is a temporary or a permanent phenomenon. The two approaches - the time-series behavior of credit outstanding and a two-stage program selection and access model-yield the same conclusion: the use of $I M F$ resources is likely to decline sharply. Specifically, credit outstanding is projected to decline from an average of SDR 50 billion over 2000-05 to an average of about SDR 8 billion over 2006-10. Stochastic simulations suggest that it is unlikely to be much higher. These results are based on the IMF's World Economic Outlook projections with a correction for historically observed overoptimistic biases. In addition, alternative scenarios assuming weaker economic performance or a less benign global economic environment do not materially alter these results. [JEL F00, F33, F34, F42]

IMF Staff Papers (2008) 55, 1-49; doi:10.1057/palgrave.imfsp.9450031

${ }^{*}$ At the time this paper was prepared, Atish Ghosh was division chief, and Juan Zalduendo a deputy division chief, of the Policy Review Division of the IMF's Policy Development and Review Department. Manuela Goretti and Bikas Joshi were economists, and Alun Thomas a senior economist, with the Policy Review Division. The authors would like to thank Mark Allen, Jorge Márquez-Ruarte, Russell Kincaid, Jonathan Ostry, Gary Schinasi, Jim Boughton, Andy Berg, and other IMF colleagues for useful suggestions during the preparation of this paper, and Sibabrata Das for research assistance. Comments and suggestions from an anonymous referee are also deeply appreciated. The literature survey (Appendix II) is an abbreviated version of a survey prepared by Patricia Brukoff, Julie Kozack, Alex Pitt, and Björn Rother. 
he recent decline in outstanding IMF resources raises the question of whether this is a temporary phenomenon-perhaps reflecting an exceptionally benign global environment - or a more permament shift in the use of IMF resources owing to improved macroeconomic performance and increased resiliency to shocks among many middle-income IMF member countries. When referring to the use of IMF resources (or UFR), the focus of this paper is exclusively on the General Resource Account (or GRA) because this constitutes the institution's income base. In particular, the Poverty Reduction and Growth Facility (PRGF) arrangements in low-income countries are excluded because these (1) are provided on concessional terms, (2) do not provide any income to the institution, and (3) depend on a different set of factors, including their catalytic role for bilateral official financing. As previous researchers have found, modeling aggregate UFR and projecting its future demand poses analytical challenges because the nature of IMF lending is unique: ${ }^{1}$ demand for UFR is determined by balance of payments difficulties, supply of IMF resources depends on the institution's policies (for instance, on exceptional access) and on the willingness of national authorities to adopt an economic program that the IMF can support, and the rate of charge is not adjusted to equilibrate supply and demand of IMF resources.

A further complication in modeling IMF credit outstanding of GRA resources is that this portfolio has become increasingly concentrated-both because the pool of members that might draw GRA resources has shrunk (as advanced economies "graduated" from IMF support and low-income countries switched to drawing concessional resources instead) and because exceptional access cases have come to dominate the portfolio. ${ }^{2}$ This portfolio concentration means that aggregate UFR depends on shocks that affect just a few members' balance of payments needs (and the precise timing of those needs) rather than on a "law of large numbers" averaging of idiosyncratic shocks across many members. Relatedly, the very large capital account crisis programs are especially difficult to handle econometrically because there are only 16 such cases (in a sample of 236 GRA arrangements over the period 1972-2005) - though they account for a large portion of IMF credit outstanding over the past decade. In addition, any proposed model specification needs to be parsimonious, because the explanatory variables

\footnotetext{
${ }^{1}$ Appendix II reviews previous studies of use of IMF credit. Worth noting is the study by Elekdağ (2006), on which the second approach developed here draws in modeling the decision to have an IMF-supported program; the second approach discussed in this paper builds on the analysis of Joshi and Zalduendo (2006). Other recent work includes Cerutti (2007) and a paper by Conway (2007) on IMF lending spells.

${ }^{2}$ Whereas during the 1980 s the three largest arrangements accounted for about onequarter of the portfolio and the 10 largest for around one-half of the portfolio, the corresponding proportions for 1995-2005 were, respectively, more than one-half and three-quarters of the portfolio.
} 
must themselves be forecastable in order to project aggregate use of IMF resources.

Given these challenges, this paper adopts two distinct analytical approaches to modeling the outstanding stock of IMF credit. The first considers the behavior of aggregate UFR directly. This has the advantage of modeling the variable - aggregate IMF credit outstanding - that is of direct relevance for IMF income and liquidity. By focusing on aggregate net credit outstanding, the approach captures implicitly gross purchases and repurchases-obviating the need to model these separately, but requiring the assumption of a stable process for members' patterns of purchases and repurchases. Although repurchases must be made no later than the date required by the obligations schedule, in a number of recent cases the member has chosen to make repurchases ahead of schedule, whereas in other caseswhere the member faced a continuing balance of payments need - a new arrangement allowed it to keep its IMF credit outstanding roughly constant while making scheduled repurchases. Moreover, changes in certain IMF policies in the past few years, including on charges, expectation-based repurchases, and post-program monitoring are likely to have had an impact on members' repurchase behavior. Finally, as the number of potential GRAdrawing members has shrunk, but average access has increased, aggregate UFR may be a relatively more stable time series than individual members' use of IMF resources.

Underlying this approach is a model of the world in which there is a large pool of (relatively homogenous) potential GRA users that are subject to idiosyncratic shocks. Thus, when one member is experiencing balance of payments problems requiring IMF support, others are likely to be recovering from their balance of payments difficulties, rendering the aggregate portfolio both fairly stable and largely determined by the average economic performance of the group of countries (as well as global factors). Although this was probably the case in earlier years, when limited private capital flows meant that contagion was less likely and the potential GRA users included almost the whole membership, the trend toward fewer-and in some cases, financially larger - programs makes this model potentially less applicable.

To take into account the fact that the world is "populated by heterogeneous UFR users," the time-series analysis of aggregate UFR is complemented by a more "bottom-up" approach that models individual members' use of IMF resources and then aggregates across the membership. ${ }^{3}$ Specifically, a discrete-choice model (using a logit specification) is used to determine the likelihood that a member will have an IMF-supported

\footnotetext{
${ }^{3}$ Because this paper seeks to project likely use of GRA resources over the medium term, the aggregation is restricted to members that have had at least one GRA arrangement since 1972, excluding current advanced economies and PRGF-eligible countries. Over the longer term, demand for GRA resources may come from current low-income countries that "graduate" from PRGF eligibility (and possibly middle-income countries that have not had an arrangement since 1970), but this is not considered here.
} 
program, in effect modeling the joint decision by an IMF member to request an arrangement and by the IMF to grant such a request. Stochastic simulations are used to generate the probability density function of programs across the relevant IMF membership. Regression analysis is then used to predict the level of access conditional on program approval, and the predicted access is then aggregated across the relevant membership. Finally, the probability density function of aggregate approved access is translated into IMF credit outstanding by assuming a disbursement and repayment schedule. $^{4}$

Although this "program selection and access" model does not depend on the assumption that GRA users consist of a large pool of relatively homogenous countries, it does require the ability to predict the likelihood that an individual member will face a balance of payments problem - and the extent of that problem. Experience with "early warning models" - which seek only to model the likelihood of a crisis - suggests that this is a tall order. Moreover, because this approach is based on modeling individual members' use of IMF resources, it does not take advantage of any averaging out of prediction errors across the membership - nor of the (partially) offsetting trends of fewer, but larger, programs.

A further caveat is that both the time series and program selection and access models should be considered reduced-form estimates of the joint decision of national authorities to request the IMF's financial support of their economic program, and of the IMF to provide that support. Ideally, these would be modeled separately, with their conjuncture determining the equilibrium outcome of an IMF-supported program (with associated access). In practice, however, it is hard to find convincing identifying restrictions, and-as discussed below-simply imposing such restrictions leads to convergence problems in the estimation and to unstable parameter estimates. ${ }^{5}$ Moreover, although desirable, identifying separate demand and supply functions for UFR is less critical here, because the main purpose of the

\footnotetext{
${ }^{4}$ Disbursement ratios (amount disbursed as a fraction of original approved access) are typically less than 100 percent, either because the IMF-supported program goes off track or because members treat the arrangement as precautionary. Conversely, in some cases, the disbursement ratio exceeds unity because access is augmented after the original program is approved. Empirically, as later discussed, the aggregate disbursement ratio is about 75-80 percent.

${ }^{5}$ Only Przeworski and Vreeland (2000) estimate separate "demand" and "supply" equations for IMF-supported programs, but they impose implausible assumptions that a member's balance of payments deficit or political regime do not influence its decision to seek IMF support - but that these variables enter into the IMF's decision about whether to provide such support. Conversely, the member's decision to seek IMF support depends on its level of reserves, its budget deficit, and its debt service - variables that are assumed not to enter into the IMF's decision. It is possible to estimate the program selection and access model without imposing identifying restrictions. However, as Maddala (1983, p. 282) notes, doing so typically does not produce good parameter estimates. Nonetheless, as a robustness check, the results of such a partially observed bivariate probit estimation are carried out with results broadly in line with the estimations discussed in the paper.
} 
models is to project use of IMF resources that reflects the equilibrium outcome of demand and supply, given forecasts of explanatory variables that might affect both. ${ }^{6}$

The difficulties inherent in forecasting aggregate use of IMF resourcesand the limitations of either approach - mean that any projections of UFR will necessarily be subject to a significant degree of uncertainty. Moreover, they will be only as good as the projections for the explanatory variables in the regressions. These are based mainly on country teams' World Economic Outlook (WEO) (October 2006) projections, which, however, have been shown in previous studies to be subject to some optimistic biases, in particular as the forecast horizon lengthens. ${ }^{7}$ Bearing these caveats in mind, the main findings can be summarized in the paragraphs that follow.

Time-series analysis suggests that there is a long-run positive relationship between aggregate UFR and middle-income countries' external debt (in percent of GDP), short-term debt (in percent of reserves), and IMF quota (or trade openness, in percent of GDP). Short-run dynamics around this long-run relationship depend on the change in the current account balance and on the imports coverage of reserves. The fit of the model is generally good, explaining 70 percent of the variation in IMF credit outstanding.

The two-stage "program selection and access" model finds that a member is more likely to have an IMF-supported program the higher its external debt, the lower its reserves coverage of imports, the greater its external and fiscal adjustment, the higher the price of oil for oil importers (the lower the price of oil, for oil exporters), and the higher its inflation rate. In 73 percent of cases in which the member had a program, the estimated probability is higher than the threshold probability implied by the sample frequency of programs; in 67 percent of cases in which the member did not have a program, the estimated probability is lower than the threshold.

Controlling for the factors that determine participation in an IMFsupported program, access to IMF resources is larger the higher the country's external debt and the greater its external adjustment. Access is also higher for systemically large countries with high external debt (proxied by countries in top deciles of the sample in terms of the U.S. dollar value of GDP and an external debt ratio higher than 40 percent of GDP).

The time-series analysis and the program selection and access model yield similar projections of aggregate use of IMF resources for the next five years. Specifically, based on current WEO projections for the main explanatory variables, both models predict an average of about SDR 8 billion. By comparison, over the period 2000-05, outstanding credit averaged SDR 50 billion.

\footnotetext{
${ }^{6}$ By way of analogy, determining the effect of an increase in the price of apples on the demand for, and supply of, apples requires estimating demand and supply functions. But determining the effect of an increase in income - which may affect demand or supply (or both) - requires only a reduced-form model.

${ }^{7}$ See Joshi and Ghosh (2003), Ghosh and others (2005), and IMF (2005a).
} 
A less benign scenario for the macroeconomic performance of potential GRA users (in particular, applying a correction for biases observed in previous WEO projections) yields aggregate IMF credit outstanding for the next five years that is about SDR 1 billion higher than in the above-baseline forecast.

\section{Aggregate Use of IMF Resources-Past and Current Trends}

Aggregate use of IMF credit has varied widely in the past, and the recent downturn is certainly not the first time there has been a nominal and real (deflated by the CPIs of the SDR constituent countries) decline in aggregate UFR (Figure 1). For the first few years after the IMF opened its doors in 1947, there was very limited use of IMF credit (that is, drawings beyond members' gold tranche) - and hence little income-because most developing countries had emerged from the World War II commodity boom with substantial foreign exchange reserves, and European countries that had access to Marshall Plan funds were discouraged from drawing IMF resources. ${ }^{8}$

Aggregate UFR picked up during the 1960s, as countries experienced balance of payments difficulties and the Bretton Woods system came increasingly under strain. The collapse of Bretton Woods itself-together with the move to floating exchange rates by the industrialized countriesreduced the demand for use of IMF resources; however, the number of arrangements and IMF credit outstanding soon picked up again in the aftermath of the 1973 and 1979 oil shocks. The number of arrangements in place peaked during the debt crisis in the first half of the 1980s (Figure 1, bottom panel), with IMF credit outstanding reaching some SDR 50 billion, but this had almost halved to SDR 26 billion by 1989 as these countries emerged from the debt crisis, and private capital flows resumed in the early 1990s.

Demand for UFR increased anew in the first half of the 1990s, when the IMF became involved in helping members transition from centrally planned to market economies, followed by a series of exceptionally large programs to deal with capital account crises-beginning with Mexico in 1995 and including the Asian crisis countries, Argentina, Brazil, and Turkey. In real SDR terms, aggregate use of IMF resources peaked in 1998 at SDR 62 billion, falling to SDR 43 billion in 2000, and increasing to almost SDR 62 billion in 2003 before plummeting to less than SDR 30 billion in 2005 owing to early repurchases. Additional early repurchases during 2006 have brought down further the level of outstanding IMF resources, to about SDR 11 billion as of end-2006.

\footnotetext{
${ }^{8}$ Indeed, by the end of fiscal year 1951, the IMF had a cumulative net deficit of $\$ 7.2$ million-which "caused some anxiety in the Board, and influenced its decisions on such matters as the size of the staff and the amount of traveling that was undertaken" (Horsefield, 1969, p. 304).
} 
Figure 1. Credit Outstanding General Resources Account (GRA), 1950-2006
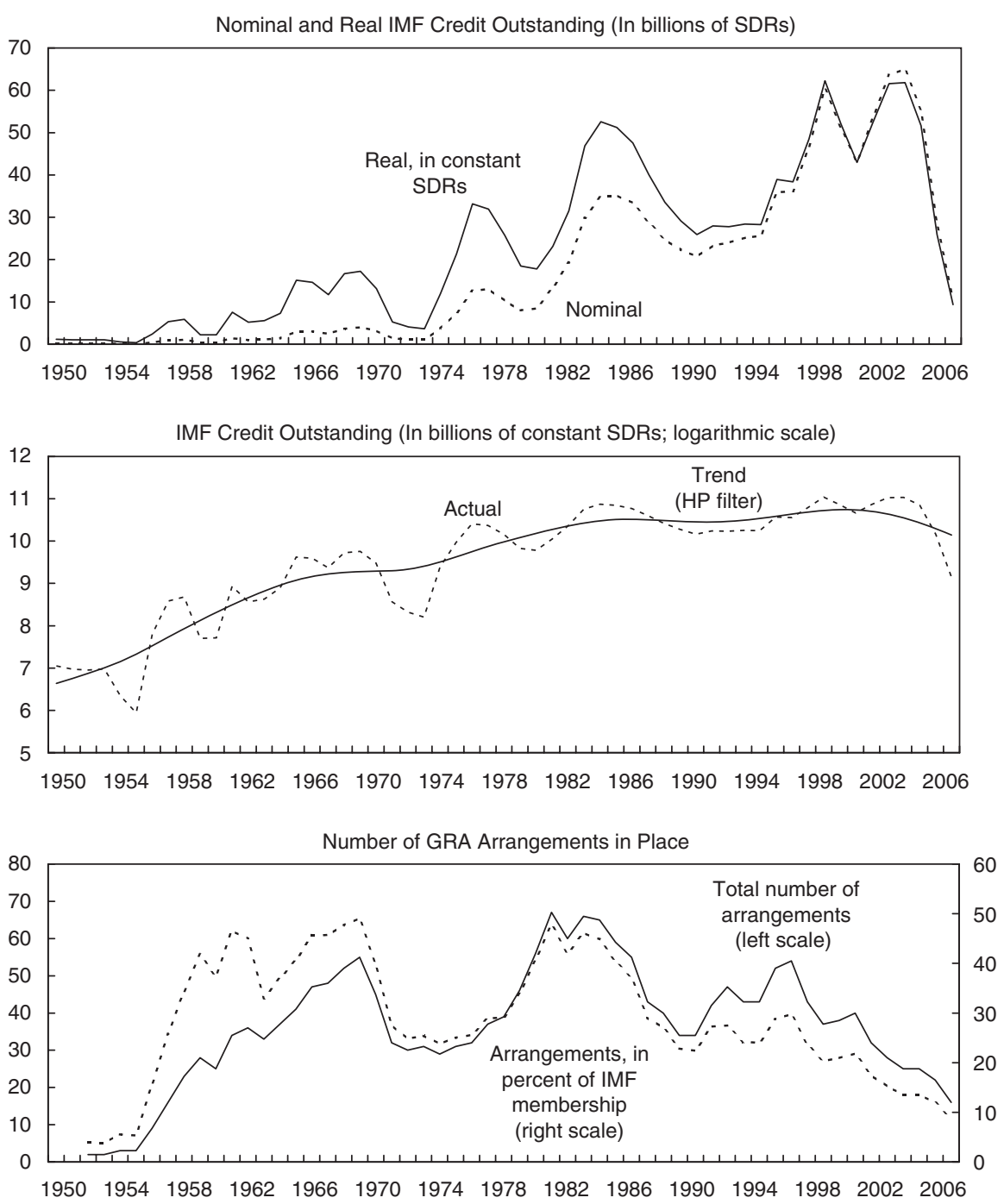

Sources: IMF, International Financial Statistics and World Economic Outlook databases for credit outstanding; IMF Finance Department database for the number of arrangements.

Note: The SDR price index is calculated using a weighted average of the consumer price inflation rates of SDR constituent countries. $\mathrm{HP}=$ Hodrick-Prescott.

Included in this long time series of UFR are arrangements with advanced economies and low-income countries. But advanced economies have not tapped IMF resources since the early 1980s, whereas low-income countries typically access concessional (non-GRA) resources. ${ }^{9}$ For the purposes of

${ }^{9}$ These include the Structural Adjustment Facility, Extended Structural Adjustment Facility, and, more recently, the Poverty Reduction and Growth Facility. 
projecting future use of GRA resources, therefore, it is useful to focus on middle-income countries - more precisely, a sample of "potential GRA users," which is defined here as members that have had at least one GRA arrangement (including first-credit-tranche arrangements) since 1972 but excluding current advanced economies and current PRGF-eligible countries. $^{10}$

Although this sample captures most members that might plausibly request use of GRA resources over the next five years, it does not take account of low-income countries that, over the longer term, are likely to improve their financial situation, allowing them to access nonconcessional IMF support if they run into balance of payments difficulties. Conversely, the sample of potential GRA users includes countries that are unlikely to turn to the IMF, even in a crisis. In some cases, this has been manifested in improved economic performance and greater resiliency to shocks, for instance by building up large, precautionary holdings of foreign exchange reserves; in the econometric analysis below, the model would (correctly) predict that such members are unlikely to use IMF resources. But in other cases, a desire to avoid future IMF support may not be matched by corresponding policies or resiliency to shocks: the econometric models would predict programs for these countries, though it is difficult to know how the balance would tilt.

Although use of IMF credit by this group of "potential GRA users" rose sharply beginning in the mid-1990s, much of the increase reflected a few exceptional access arrangements (Figure 2). Indeed, the number of GRA arrangements both in absolute terms and in proportion to the number of IMF members in this group has been declining almost monotonically since the mid-1990s (Figure 2, bottom panel). As a result, and because of a greater prevalence of arrangements that authorities treat as precautionary (IMF, 2006), the concentration of the GRA portfolio has increased considerably, with the three largest arrangements accounting for more than 60 percent of the portfolio and the five largest for 75 percent (Figure 3, top panel). The small number of members drawing IMF resources (at any point in time) and the portfolio concentration, in turn, mean that projections of use of IMF resources cannot take (much) advantage of a "law of large numbers" averaging of idiosyncratic shocks across members that would make the aggregate portfolio stable.

Some of the difficulties in projecting future use of IMF credit are evident from the bottom panel of Figure 3, which considers alternative extrapolations of the time-series trend of aggregate UFR. Seemingly plausible methods of extrapolation-for instance, based on the average

\footnotetext{
${ }^{10}$ Other than Bolivia, India, Papua New Guinea, and Nigeria, PRGF-eligible countries that have accessed GRA resources since 1990 (excluding blended arrangements). Although the sample of middle-income countries in the World Development Indicators is much larger (about 90 countries instead of the 53 covered in this paper), the difference reflects mostly small economies that would have only a marginal effect on aggregate UFR; in fact, the countries in this paper account for about 90 percent of the IMF quota of middle-income countries.
} 
Figure 2. General Resources Account (GRA) Credit Outstanding: Middle-Income Country Sample, 1970-2006
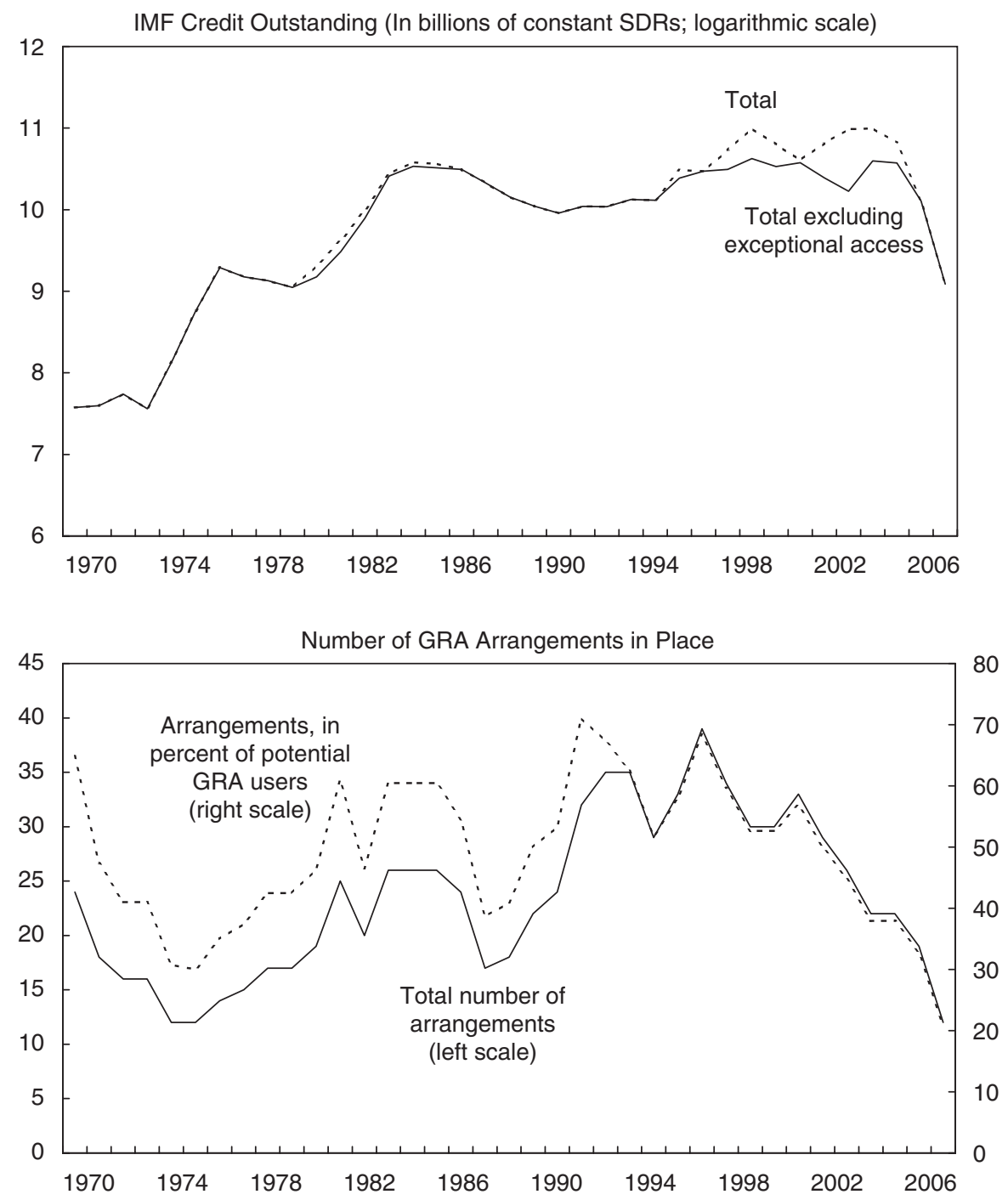

Sources: IMF, International Financial Statistics and World Economic Outlook databases for credit outstanding; IMF Finance Department database for the number of programs.

growth rate of the sample or the average growth rate of the trend - can lead to very different projections. Therefore, economics-based models are developed below.

\section{Time-Series Model of Aggregate UFR}

One approach to modeling UFR is to consider the time-series behavior of the aggregate stock of outstanding IMF credit (to the group of potential GRA 
Figure 3. General Resources Account (GRA) Credit Outstanding: Number, Concentration, and Trends

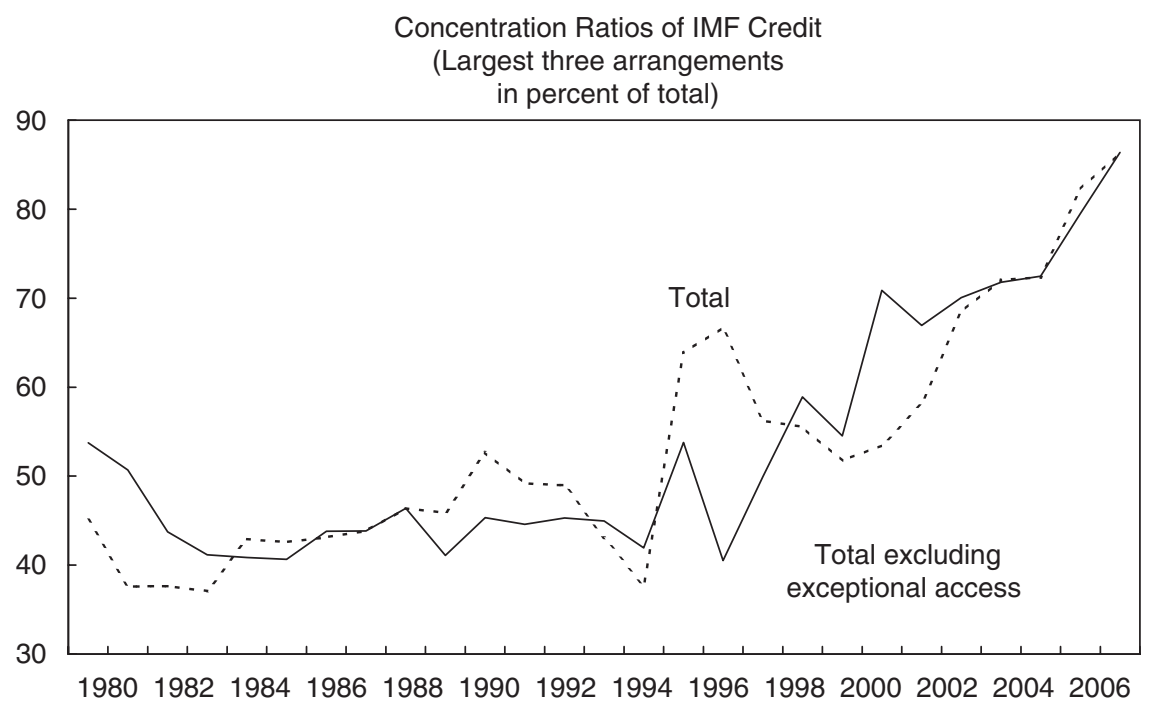

GRA Credit Outstanding: Alternative Trends (In billions of SDRs)

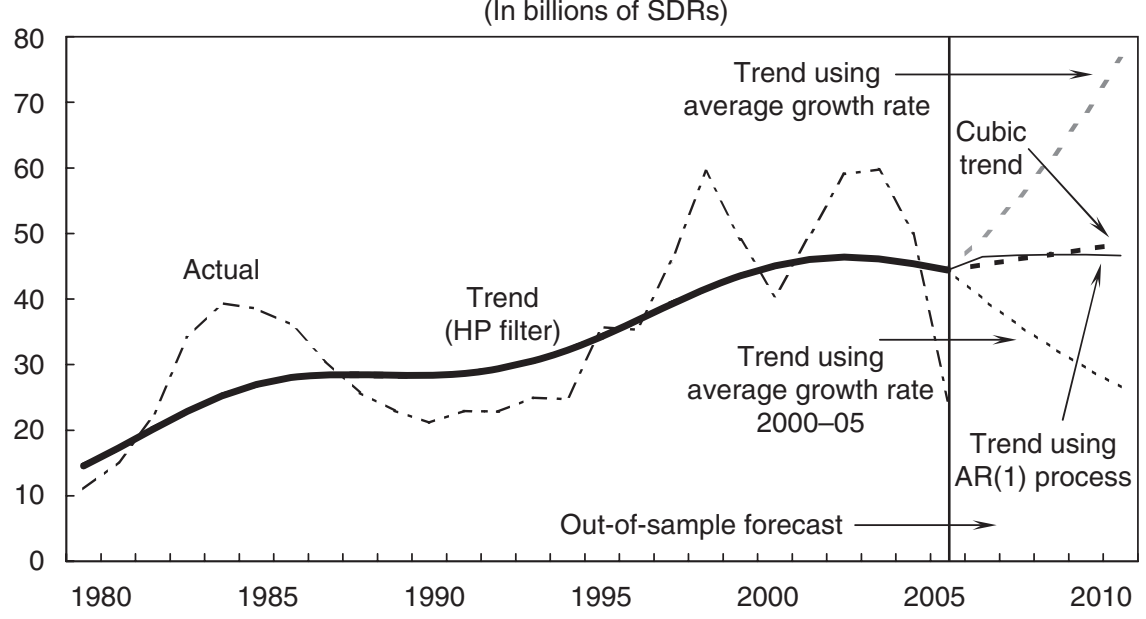

Sources: IMF, International Financial Statistics, World Economic Outlook databases; and IMF Finance Department database.

Note: The SDR price index is calculated using a weighted average of the consumer price inflation rates of SDR constituent countries. The lower panel presents the Hodrick-Prescott (HP) filtered trend for IMF credit outstanding over the sample period. Out-of-sample projections of the trend have been produced using different methodologies. In particular, the alternative trends presented in the lower panel have been calculated by (1) applying the average growth rate of the series over the sample period; (2) applying the average growth rate of the series in the previous five years; (3) estimating an AR(1) process for the filtered series, including a constant and a trend; and (4) regressing the filtered series on a cubic trend. 
users, as defined above). ${ }^{11}$ This has the advantage of modeling the variable that is of direct relevance to IMF income, and of not requiring projections of individual members' IMF drawings or repurchases. Standard time-series techniques can be applied to obtain long-run (cointegrating) relationships between IMF credit outstanding and various explanatory variables capturing the average economic performance of this group of countries (as well as global market conditions), with convergence to the long-run relationship determined by autonomous dynamics (that depend on the distance from the long-run relationship) and by short-run factors.

Yet there are caveats to this approach. First, as noted above, the group of countries needs to be sufficiently homogenous that IMF credit outstanding can be related to the aggregate (that is, average) economic performance of the group. ${ }^{12}$ Although the group consists of middle-income countries, they are quite diverse, with quotas ranging from SDR 20 million to SDR 6.4 billion, GDPs from $\$ 1$ billion to $\$ 2,000$ billion, and potentially very different external financing needs.

Second, given that - at any moment - a member either does or does not access IMF credit, in what sense can there be short-run and long-run dynamics of total IMF credit outstanding? Here, an analogy to macroeconomic models of unemployment may be useful. At any moment, an individual is either employed or unemployed-and the probability of entering or exiting a spell of unemployment depends on a variety of factorsboth macroeconomic and idiosyncratic. Nevertheless, it makes sense to model the short-run and long-run response of the aggregate unemployment rate to macroeconomic factors - on the assumption that the idiosyncratic shocks average out across individuals. Likewise, short-run and long-run dynamics of aggregate IMF credit can be modeled as functions of global conditions and the average economic performance of potential GRA users, although with the important caveat that national unemployment rates represent the aggregation (with equal weight) of millions of individuals - not of some 50 countries of very different sizes.

Third, the shift toward fewer but larger programs in recent years suggests that the time-series process underlying aggregate UFR may have changed over time-yet the analysis treats the process as a single series spanning 1980-2005. Indeed, there is evidence that the time-series process of aggregate UFR during periods of large exceptional access programs differs from the

\footnotetext{
${ }^{11}$ Because the dependent variable is IMF GRA credit outstanding (to the group of potential GRA users) it does not include amounts approved but not drawn (including resources that would be available under a precautionary arrangement).

${ }^{12}$ For example, suppose that IMF credit outstanding is related to the external debt ratio and that, between two periods, this debt ratio does not change because one country's external debt increases while another's decreases - then the model would imply that IMF credit outstanding should not change either. But the country with the rising debt ratio may be a large, systemically important country that experiences a capital account crisis requiring large IMF access - which would not necessarily be offset by the lower use of IMF credit by the country with the falling external debt ratio (particularly because UFR cannot be negative).
} 
process during other times - though this distinction is less useful when projecting future UFR, because it is difficult to forecast which process will pertain (Appendix I).

Fourth, beyond exceptional access policy—which affects the amount of IMF financing made available - other IMF policy changes in recent years, including surcharges on IMF resources outstanding, time-based repurchase expectations, and postprogram monitoring, are likely to have influenced members' repurchase behavior (IMF, 2000, 2002, and 2003). These are difficult to capture econometrically because these policy changes are too recent, but could help account for some of the early repurchases currently being made by members with IMF credit outstanding. Finally, there are only 25 observations, given the estimation period of 1980-2005; although it is possible to extend the time series backward, the assumption of a stable series becomes less tenable.

With these caveats in mind, a long-run relationship is estimated between the logarithm of IMF credit outstanding and external debt and IMF quotas (in percent of GDP), short-term debt (in percent of reserves), and the IMF's rate of charge relative to the 10-year U.S. corporate bond yield (which proxies for the cost of IMF resources relative to market financing). ${ }^{13}$ These variables are computed over 1980-2005 for the group of potential GRA users (Table 1, top panel). Because each of these variables is individually nonstationary, standard statistical inferences (for example, $t$-statistics) are not valid (Phillips, 1986). The stationarity of the residuals from the cointegrating vector, however, indicates that a cointegrating relationship exists. In particular, IMF credit outstanding to this group of countries increases as they have more external debt, lower foreign exchange reserves (in relation to short-term debt), a larger IMF quota, and a lower IMF rate of charge. This is intuitive, because these countries' balance of payments need is likely to be increasing in their external debt (in relation to reserves), whereas their willingness to keep credit outstanding is decreasing in the rate of charge. As regards the quota variable, this may be proxying for trade and financial openness, which may be a determinant of the demand for UFR; indeed, substituting trade openness for IMF quota yields very similar results.

Short-run factors influencing the speed of convergence to the long-run relationship are postulated to depend on terms of trade shocks, the change in the current account balance, and the change in reserves (in months of imports). Of these, only the change in reserves is statistically significant, although all variables have the correct sign. A positive terms of trade shock is associated with less demand for IMF credit, whereas a decrease in reserve

\footnotetext{
${ }^{13}$ The IMF's rate of charge includes the adjusted rate of charge plus the outstandingcredit-weighted average of surcharges. As regards the corporate bond yield, although the emerging market bond spreads would be preferable, they are not available for most emerging market - let alone middle-income - countries over the sample period. Using the 10-year U.S. treasury bill rate instead yields very similar results.
} 
MODELING AGGREGATE USE OF IMF RESOURCES

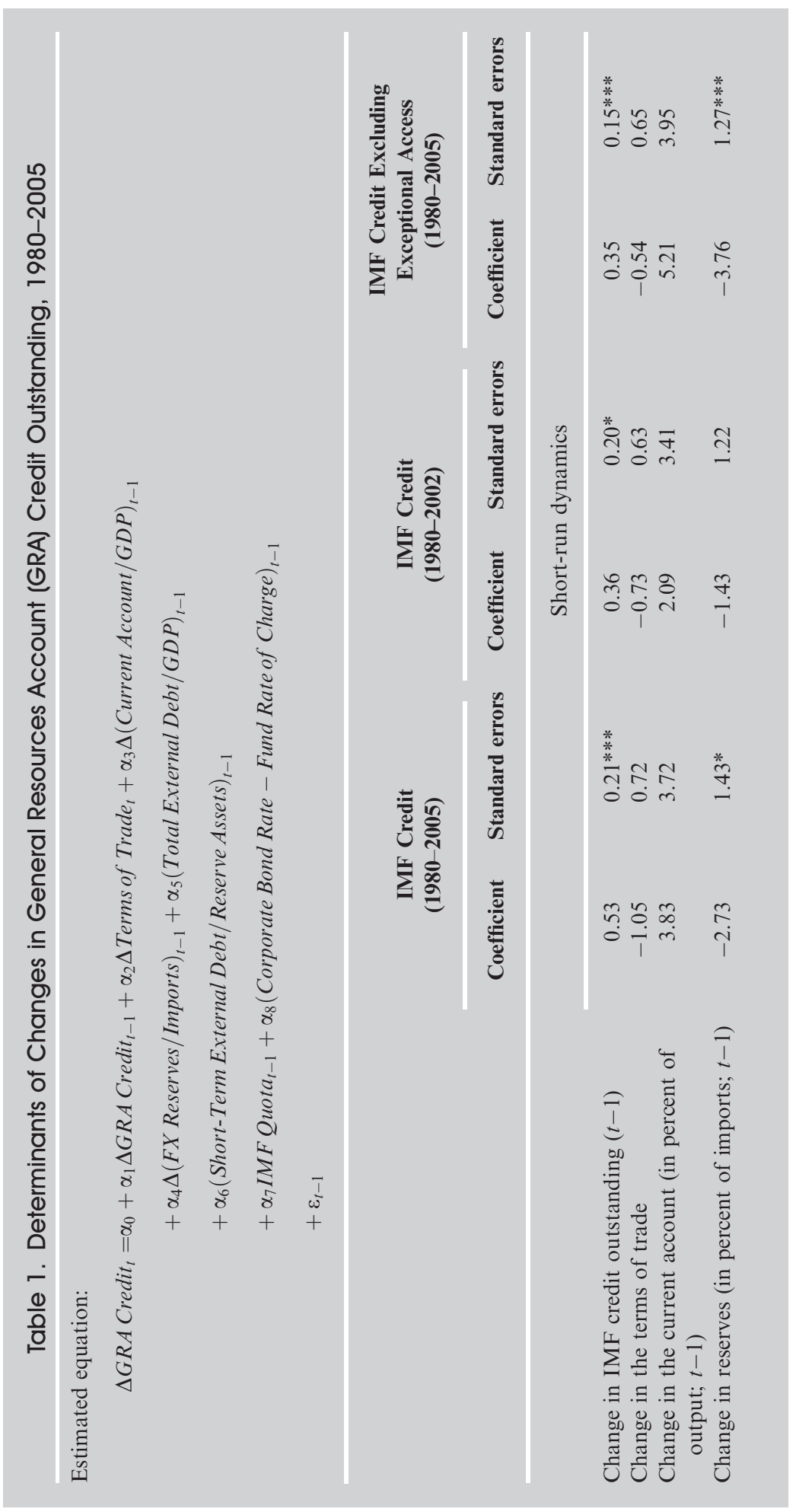


Atish Ghosh and others

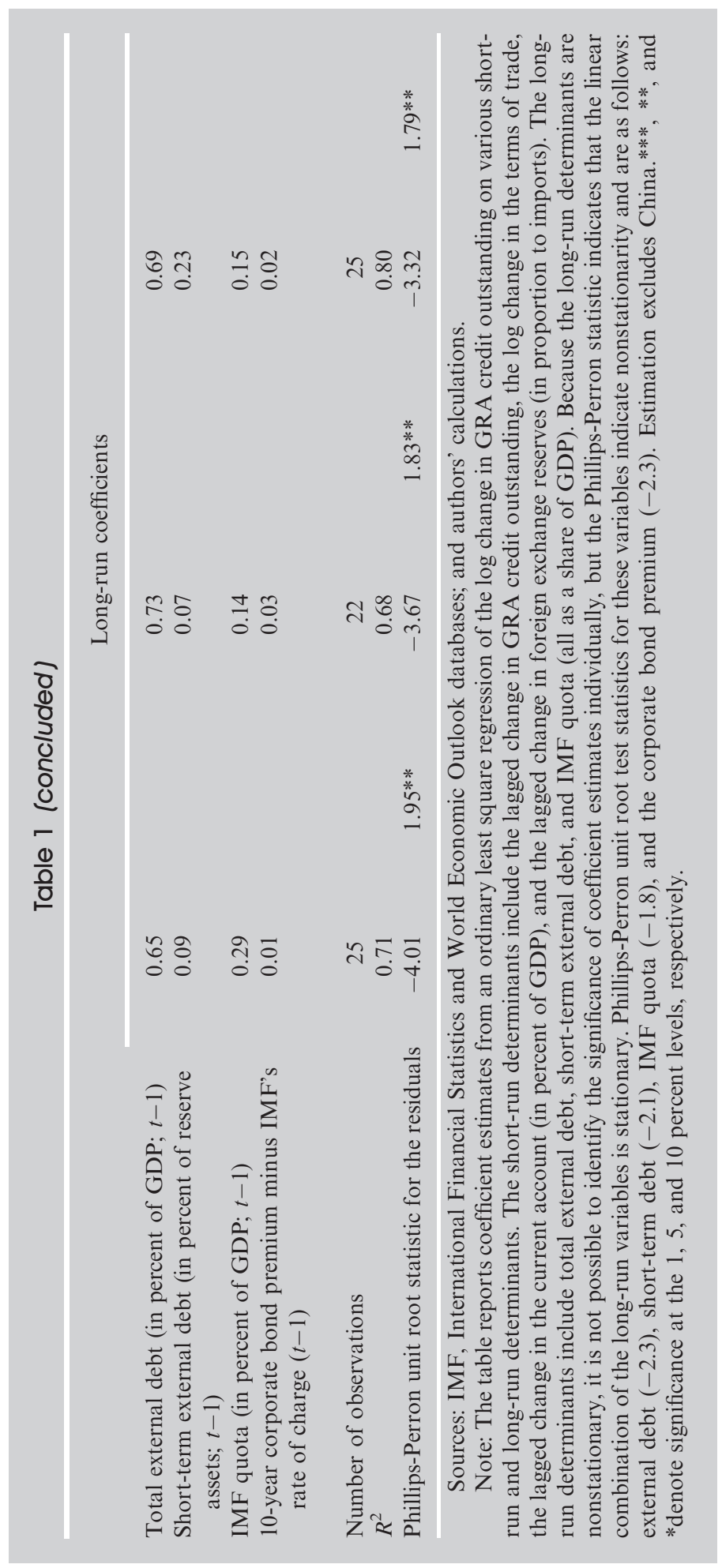


cover or an improvement in the current account balance are both associated with greater use of IMF credit. Although the latter may appear counterintuitive, it is consistent with the empirical finding that the current account deficit typically narrows in the run-up to an IMF-supported program-either because the withdrawal of private financing forces external adjustment or because national authorities tighten policies to promote adjustment before turning to the IMF (Ghosh and others, 2005).

Comparing actual levels of IMF credit outstanding to the model's longrun prediction (Figure 4, top panel), it is evident that much of the very high level of UFR over the period 2001-05 should have been expected to be temporary in that it far exceeded the level implied by the equilibrium cointegrating relationship. Whereas the long-run relationship would suggest aggregate UFR of about SDR 40 billion in 2001-03, actual credit outstanding was in the range of SDR 50-63 billion. Thus, the model's autonomous dynamics would - other things being equal - tend to decrease UFR toward the level implied by the long-run relationship. Indeed, taking account of short-run dynamics, actual UFR exceeded the model's prediction by an average of SDR 11 billion over 2001-05.

Overall, the fit of the model is good, accounting for some 68 percent of the variation in IMF credit outstanding (and more than 80 percent if exceptional access programs are excluded). Given the large number of variables relative to observations, however, a more telling test of the model's performance is the accuracy of out-of-sample projections. For this purpose, the model was reestimated over 1980-2002, and the coefficients used to project IMF credit outstanding for 2003-05. ${ }^{14}$ Although-as noted - the model does not fully account for the very high levels of IMF credit outstanding during 2001-05, it does capture the main dynamics correctly. Although the predicted peak of SDR 52 billion in 2002 is considerably below the actual peak of SDR 63 billion in 2003, the model does anticipate the subsequent downturn in UFR. The main contributors to the decline in the demand for IMF resources over 2003-05 are the fall in the ratio of total debt to output and the sharp rise in reserve assets, also resulting in a decline in the ratio of short-term debt to reserves. Indeed, long-run determinants of IMF credit were projected to contribute to a decline of 60 percent over 2003-05, and short-run determinants were projected to contribute an additional 85 percent. In fact, IMF credit fell by more than 300 percent.

\section{Modeling Individual Members' Use of IMF Resources}

To complement the time-series analysis of aggregate UFR, an alternative approach estimates the expected use of IMF resources by individual

\footnotetext{
${ }^{14}$ If the coefficients for the demand for total IMF credit are imposed in the regression of IMF credit, excluding exceptional access, then the likelihood ratio statistic is not significant.
} 
Figure 4. IMF Credit Outstanding: Actual and Fit of Time-Series Model (In billions of SDRs; General Resources Account only)
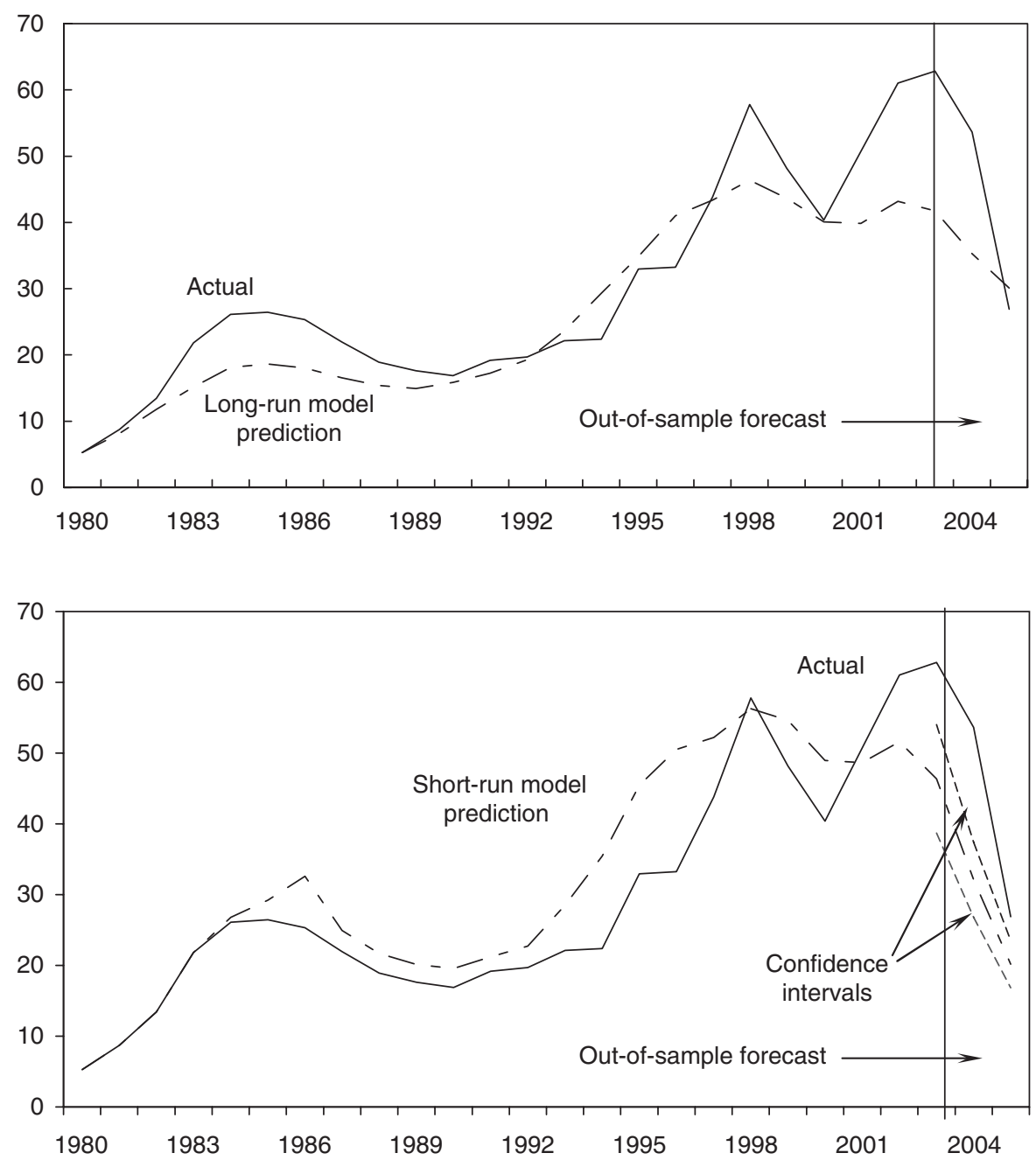

Sources: IMF, International Financial Statistics and World Economic Outlook databases.

Note: This figure presents the actual log level of General Resources Account (GRA) credit outstanding and two model profiles based on whether only long-run determinants of GRA credit are used (long-run model prediction) or both long-run and short-run determinants are used (shortrun model prediction). The models are estimated through 2003 and out-of-sample forecasts are shown for the period 2004-06. The out-of-sample prediction includes 90 percent confidence intervals derived by stochastic simulations using bootstrapping techniques.

countries, and then aggregates across the eligible membership. Specifically, in the first stage, a logit model is used to estimate the likelihood of the joint decision that a member experiencing balance of payments difficulties would request an IMF-supported program and that this request would be granted 
by the IMF Executive Board. ${ }^{15}$ In the second stage, a regression model is used to calculate the expected approved access to IMF resources, with the inverse Mills ratio from the logit estimation controlling for the sample selection bias. ${ }^{16}$ Finally, approved access is mapped into IMF credit outstanding by assuming average disbursement and repayment profiles.

In contrast to the time-series analysis, which is based on IMF credit outstanding, the dependent variable here is IMF access (a binary variable in the first stage, and the logarithm of the access amount at the time of program approval in percent of GDP). Original access approved does not map directly into disbursements because the program may go off track or because national authorities choose to treat the arrangement as precautionary (or they otherwise choose to stop drawing); conversely, disbursements may exceed the original approved amount if the arrangement is augmented. Historically, the ratio of disbursed amounts to approved access has ranged from about 70 percent (1980-90) to about 80 percent (1990-2005); in the projections below, the ratio is therefore set at 75 percent.

Table 2 reports coefficient estimates for the program-selection logit specification. A country is more likely to have an IMF-supported program the higher its external debt, the lower its reserve coverage (in terms of both short-term debt and imports), the greater its fiscal imbalances, the higher (lower) the oil prices for oil importers (exporters), and the lower the country's economic growth rate. High inflation is also associated - albeit not always statistically significantly - with a greater likelihood of a program. ${ }^{17}$ Political variables and volatility indicators of both global and domestic economic

\footnotetext{
${ }^{15}$ An alternative approach would be to estimate IMF access using a Tobit model. However, although this would provide the expected access level, it would not provide the likelihood of a program and the expected level of access (conditional on a program) separately. Moreover, a Tobit model would treat cases in which the country does not have a program as a program with zero access.

${ }^{16}$ The Heckman two-stage approach adopted here assumes that there is some process that determines whether access is observed (see Heckman, 1979). An intuitive explanation of the Heckman approach, including the use of the inverse Mills ratio (IMR), can be found in the Nobel citation by the Royal Swedish Academy of Sciences (2000, pp. 4-5). The Heckman approach can be interpreted as a special case of the omitted variable problem - with the selection criteria being the omitted factor. The first stage estimates selection, with the IMR entering in the second stage as the (previously) omitted variable. In this case, the statistically significant coefficient on the IMR variable indicates a nonrandom selection of countries into IMF-supported programs. Because both stages have the same number of observations (that is, the no program cases are also part of the second stage access estimation), the amendment suggested by Maddala (1983) to the Mills ratio is used; although the estimates are still unbiased, the proposed modification improves the asymptotic consistency of the estimates. Dubin and McFadden (1984) is an early and intuitive application of this procedure to residential electric appliance holdings and consumption.

${ }^{17}$ Indicators of political and economic proximity, such as UN votes and trade shares with the United States or western Europe, have no statistically significant effect on the likelihood that a country will request an IMF-supported program or on the size of IMF lending. Thus, the role of political and economic proximity discussed by Barro and Lee (2005) does not appear to hold in better-specified models of program selection and access.
} 
Atish Ghosh and others

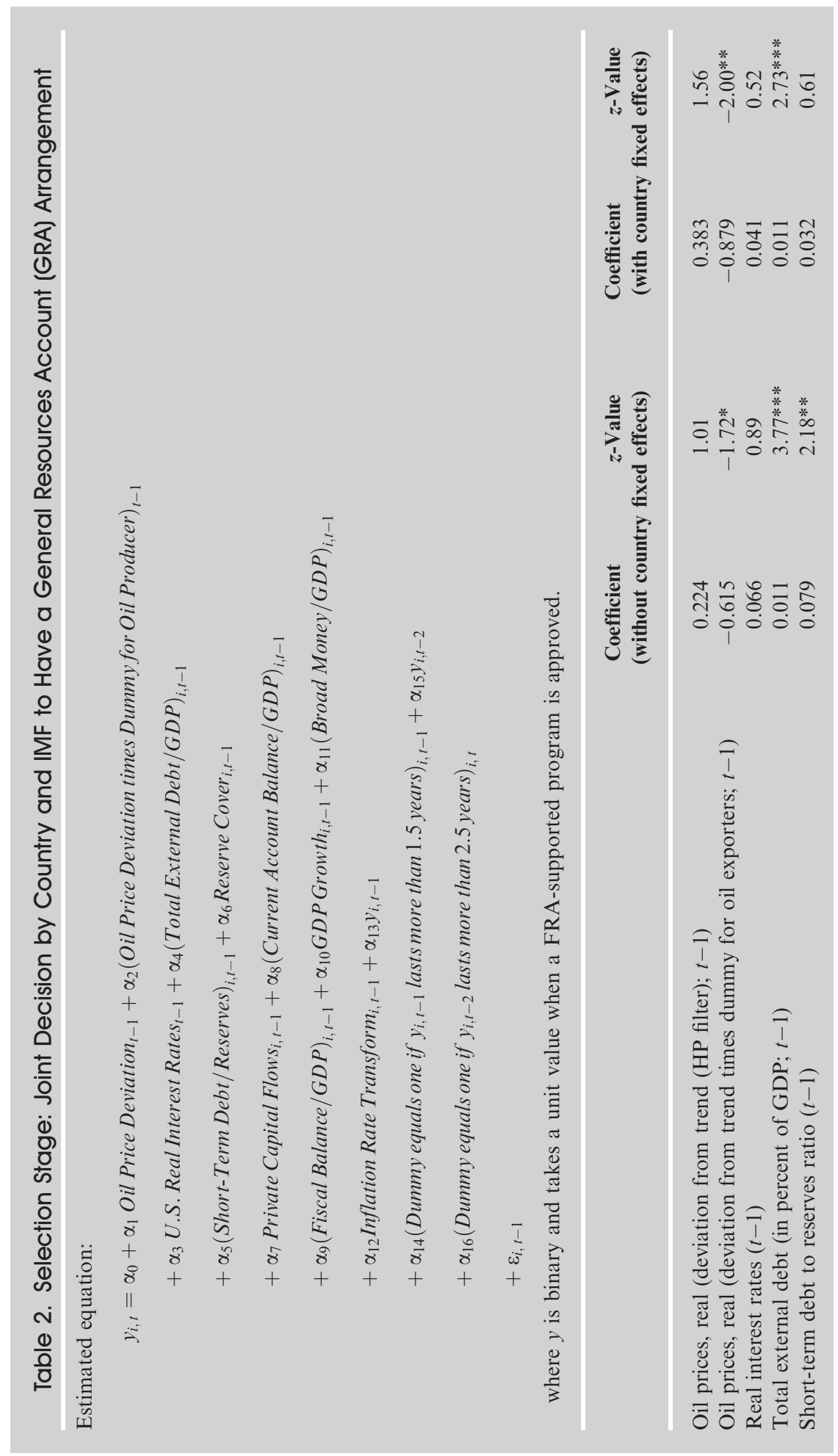




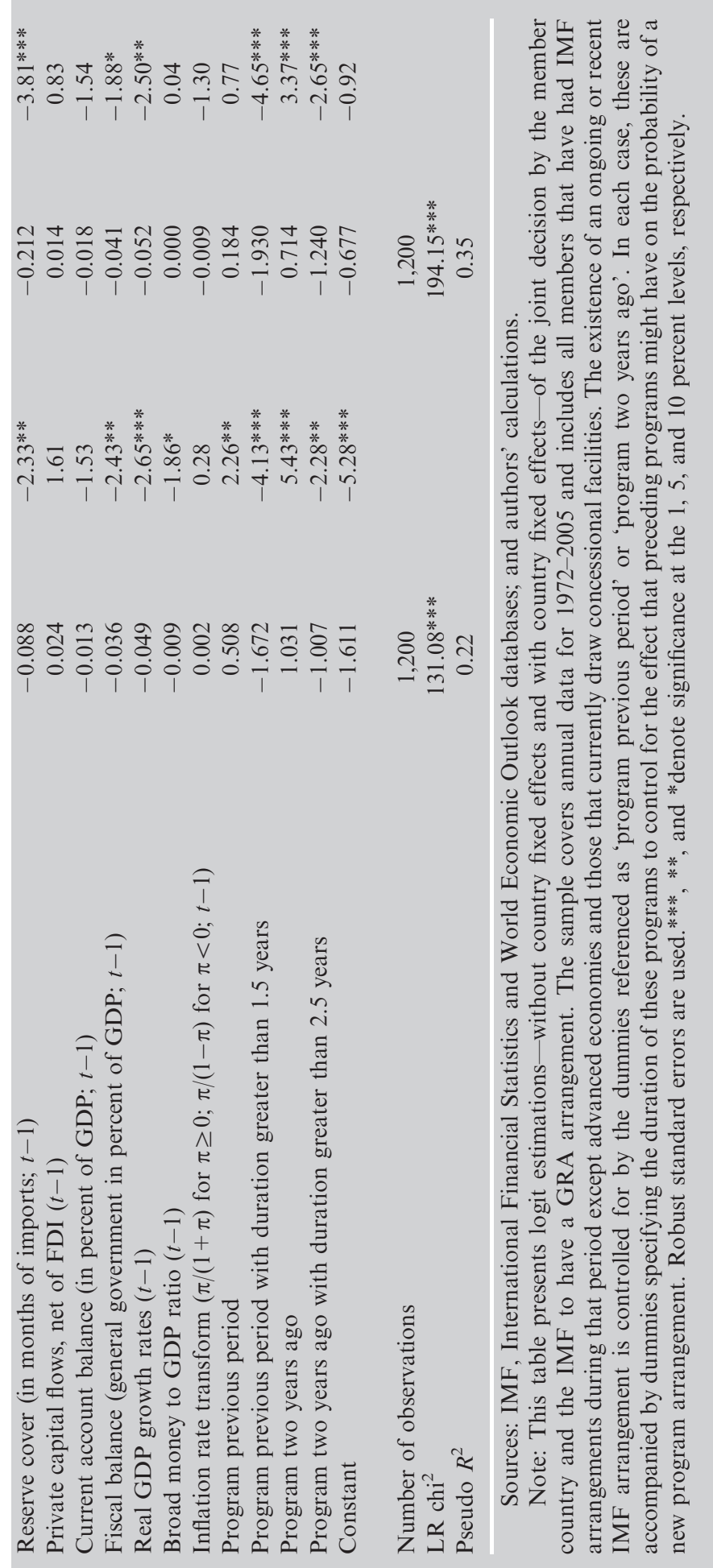


variables (volatility of inflation, interest rates, and oil prices) were also tried but were not found to be statistically significant.

The model's goodness of fit, calculated as the McKelvey-Zavoina pseudo- $R^{2}$ statistic, is 0.22 (Table 2). ${ }^{18}$ This fit improves if fixed effects are added to the estimation: a pseudo- $R^{2}$ statistic of 0.35 . More generally, a commonly used statistic of goodness of fit is the number of observations in which the member had a program and the predicted probability was higher than a threshold (usually set equal to the frequency of programs in the sample-which is 20 percent for this sample). The statistic is potentially misleading as a test of the model's predictive power for any individual member because the model predicts probabilities, not outcomes. ${ }^{19}$ Thus, when a member has a predicted probability of more than 20 percent, this does not necessarily imply that the member will have a program (or that, if it does, the model was necessarily correct in predicting the program). However, across the sample, if the predicted probability of a program is 20 percent, then, on average, 20 percent of the sample should have programs. Thus, the predicted probability can be used to forecast the aggregate portfolio-but not whether an individual member is going to have a program.

With this important caveat regarding the interpretation of the results, Table 3 reports instances in which the predicted probability is higher than the threshold and the member indeed had a program (64 percent of cases) and, conversely, where the predicted probability is lower than the threshold and the member did not have a program (71 percent of cases); out of sample, the corresponding statistics are 75 and 71 percent, respectively. In a number of instances, such as Paraguay (in 2003) and Uruguay (in 2005), the implied probability is just below the threshold (which is set to the sample frequency of programs); in other cases, the predicted probability is higher than the threshold in the year preceding the program approval. ${ }^{20}$

Predicting whether and when a member will have an IMF-supported program is only the first step. The next step is the level of access to GRA resources that will be granted. Within the normal access limits (annual access of 100 percent of quota, and a cumulative limit of 300 percent of quota), access is granted according to the member's balance of payments need, its capacity to repay the IMF, and its outstanding IMF credit, repayment record, and previous use of IMF resources. Exceptional access beyond the access limits may be granted if the member has a balance of payments need

\footnotetext{
${ }^{18}$ The literature contains many alternative measures of goodness of fit for use with equations with discrete dependent variables. There is, however, no consensus as to the relative merits of alternative measures, and most of the measures proposed have a theoretical upper bound well below unity. See Estrella (1998) and Windmeijer (1995) for a discussion of various goodness-of-fit measures in discrete choice models.

${ }^{19}$ For a discussion, see Train (2003).

${ }^{20}$ For instance, a program is "predicted" in Romania in 2003 (instead of the actual 2004 program), Paraguay in 2005 (instead of 2006), Gabon in 2003 (instead of 2004), Uruguay in 2004 (instead of 2005), and Ukraine in 2005 (instead of 2004).
} 
Table 3. Access Model, Type I and Type II Errors

In-Sample Prediction (1972-2005; without country fixed-effects)

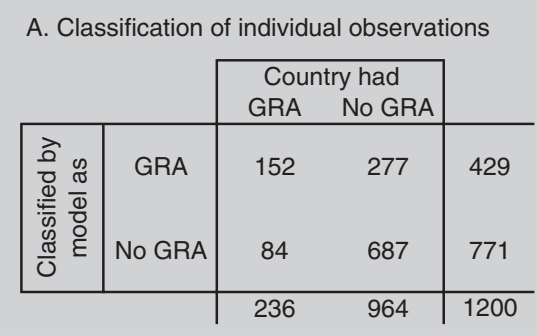

B. Type I and Type II errors (In percent)

In-Sample Prediction (1972-2005; with country fixed effects)

C. Classification of individual observations

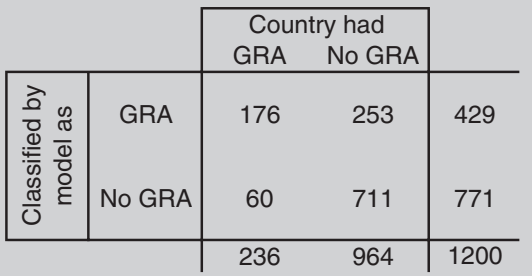

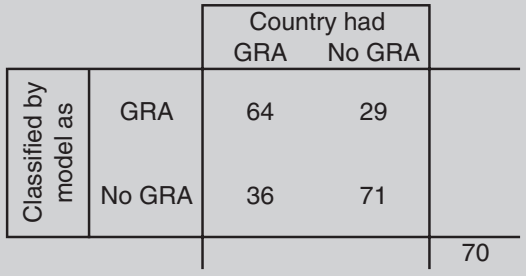

D. Type I and Type II errors (In percent)

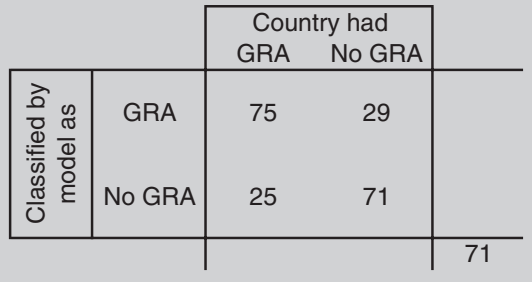

Out-of-Sample Prediction (2003-2005; without country fixed effects)

E. Classification of individual observations

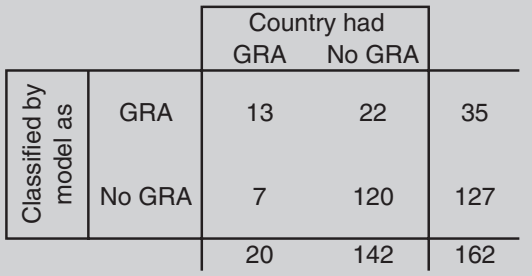

F. Type I and Type II errors (In percent)

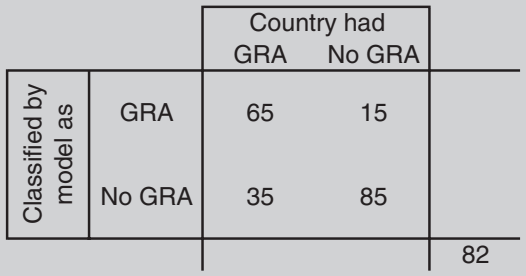

Source: Authors' calculations.

Note: This table presents the Type I and Type II errors for alternative specifications (without and with country fixed effects) and sample periods. The unconditional mean of having a General Resources Account (GRA) arrangement is the threshold used in classifying each observation. Panel A reports the in-sample predictive power of the estimation in Table 2 excluding country fixed effects. Panel $\mathrm{C}$ reports the in-sample predictive power of the estimation in Table 2 with country fixed effects. In contrast, Panel E shows out-of-sample estimations without fixed effects. The econometric estimation itself is not reported but available from the authors upon request. This estimation is the same specification as in Table 2, but covers only the period 1972-2002 and estimates 2003-05 out-of-sample and the predictive power of such estimation given the IMF-supported programs that were approved during that period. Panels B, D, and F present the data in percentage terms.

and fulfills certain criteria. ${ }^{21}$ For most programs in the 1980s, access as a percentage of quota averaged 30 percent, rising to 50 percent in the 1990s.

${ }^{21}$ See IMF (2005b, pp. 335-49) for discussions of access policy. 
The 1990s also saw large capital account crisis programs, with access many multiples of quota, which are especially difficult to handle because there are only 16 such cases in a sample of 236 arrangements, and it is hard to find variables that both can explain the amount of access provided and are themselves readily forecastable.

The access regression uses a generalized least squares estimation. As shown in Table 4, access (as a percentage of the country's GDP) is positively and statistically significantly related to the country's initial external debt and the external adjustment it undertakes in the year of program approval (relative to its current account deficit in the preceding three years). The decision to model access as a share of GDP was in part driven by the fact that quotas are not an adequate representation of a country in the global economy and, as a result, they have only a limited link to a country's potential resource needs. ${ }^{22}$ The ratio of short-term debt to reserves enters the regression with a positive, albeit statistically insignificant, coefficient. Similarly, the IMF quota has a statistically insignificant, albeit negative, point estimate. Finally, to help capture exceptional access in the large capital account crisis programs, a dummy variable is defined for countries that are "systemically large" (proxied by the country being in the top decile of the sample in terms of U.S. dollar value of GDP) and whose external debt exceeds 40 percent of GDP. ${ }^{23}$ Although this dummy variable is highly significant (with its coefficient implying that access is, on average, 4 percent of GDP higher for such programs, other things being equal), it cannot fully capture the exceptionally large access provided in some capital account crises. The regression tracks movements in GRA access, explaining about 20 percent of the variation in the dependent variable (22 percent when fixed effects are added). ${ }^{24}$ Yet, within the sample, the model estimates that the programs approved during the period 2000-05 would have involved access for a total of SDR 33 billion to SDR 63 billion (the larger figure when fixed effects are added to the estimation), which compares with the total for programs approved during that period of SDR 69 billion. Applying the predicted probability weights translates into a lower predicted average UFR outstanding of about SDR 25 billion.

To generate out-of-sample projections, the program selection logit is used to generate the probability that the member will have a program and, based on those probabilities, the associated level of access; it is also assumed that a country cannot have new programs in two consecutive years. For 2003-05,

\footnotetext{
${ }^{22}$ Not surprisingly, specifications based on access as a share of quota did not provide meaningful results.

${ }^{23}$ Empirical studies suggest that, for market borrowers, there is an appreciable increase in the probability of a debt crisis when external debt exceeds 40 percent of GDP (see IMF, 2002).

${ }^{24}$ Replacing IMF quota with an openness variable (defined as a sum of exports and imports in percent of GDP) for reasons discussed earlier, however, does not change the results. The coefficient on the openness variable remains statistically insignificant, with other variables retaining their results; the measured $R^{2}$ also does not change.
} 


\section{Table 4. Access Stage: Determinants of Access Levels in a General Resources Account Arrangement}

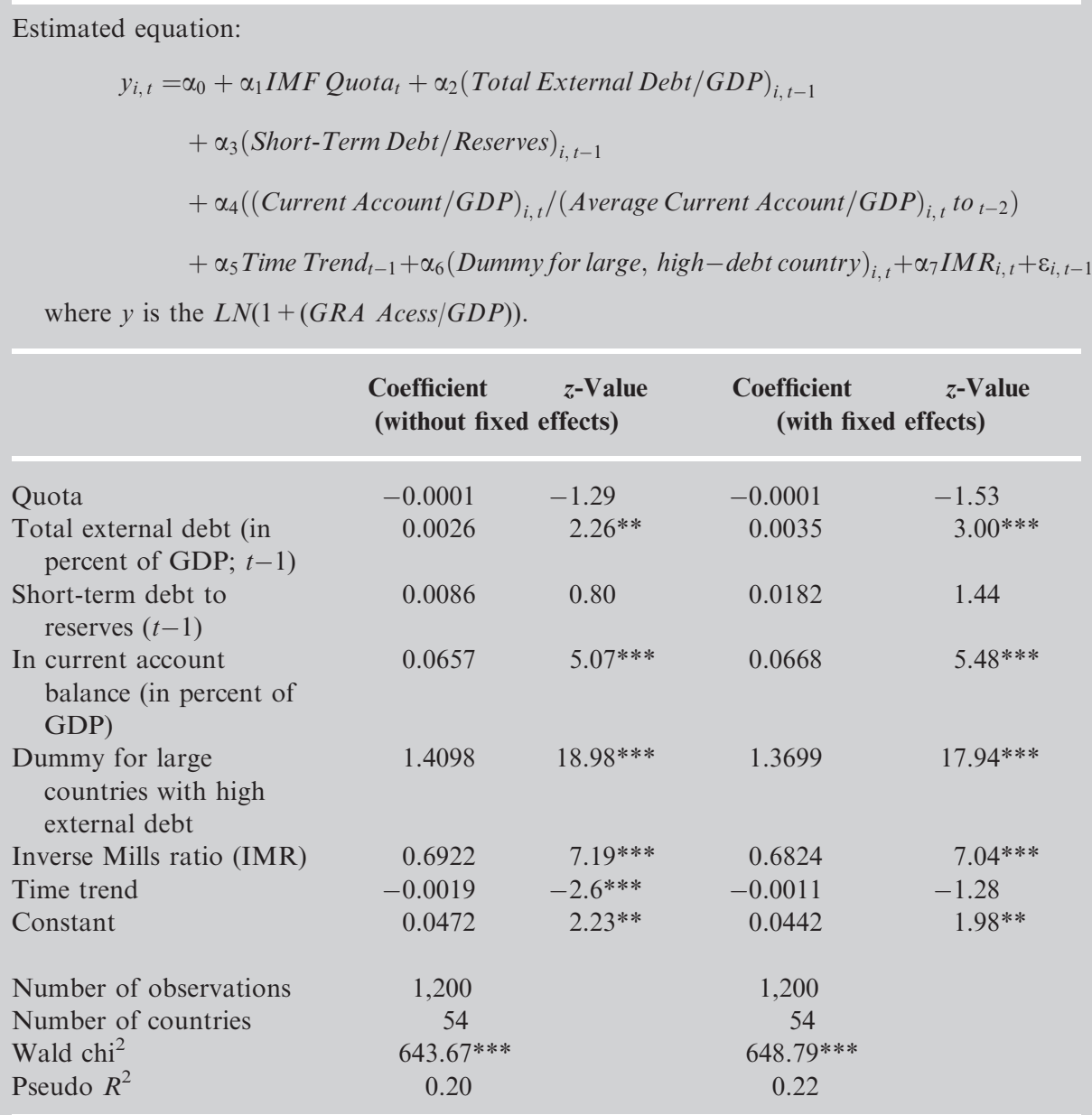

Sources: IMF; and authors' calculations.

Note: This table presents generalized least squares estimations - without and with country fixed effects - of the access to IMF resources. The inverse Mills ratio (IMR) calculated in the first stage is included to control for omitted variables. The access model includes a dummy variable for large and highly indebted countries (i.e., countries in the top decile of the sample in terms of U.S. dollar value of GDP and whose external debt exceeds 40 percent of GDP) to control for the conditions that could result in a capital account crisis that could require exceptional access to IMF resources. The generalized least square estimation specifies (1) an heteroscedastic error structure with no cross-sectional correlation, (2) an AR(1) autocorrelation within panels, and (3) robust standard errors. The sample (annual data) covers the period 1972-2005 and includes countries that have borrowed from the IMF during that period except advanced economies and those that currently draw concessional facilities.***,**, and $*$ denote significance at the 1,5 , and 10 percent levels, respectively. 
Figure 5. Approved General Resources Account Access, 1975-2005 (In billions of SDRs; General Resources Account only)

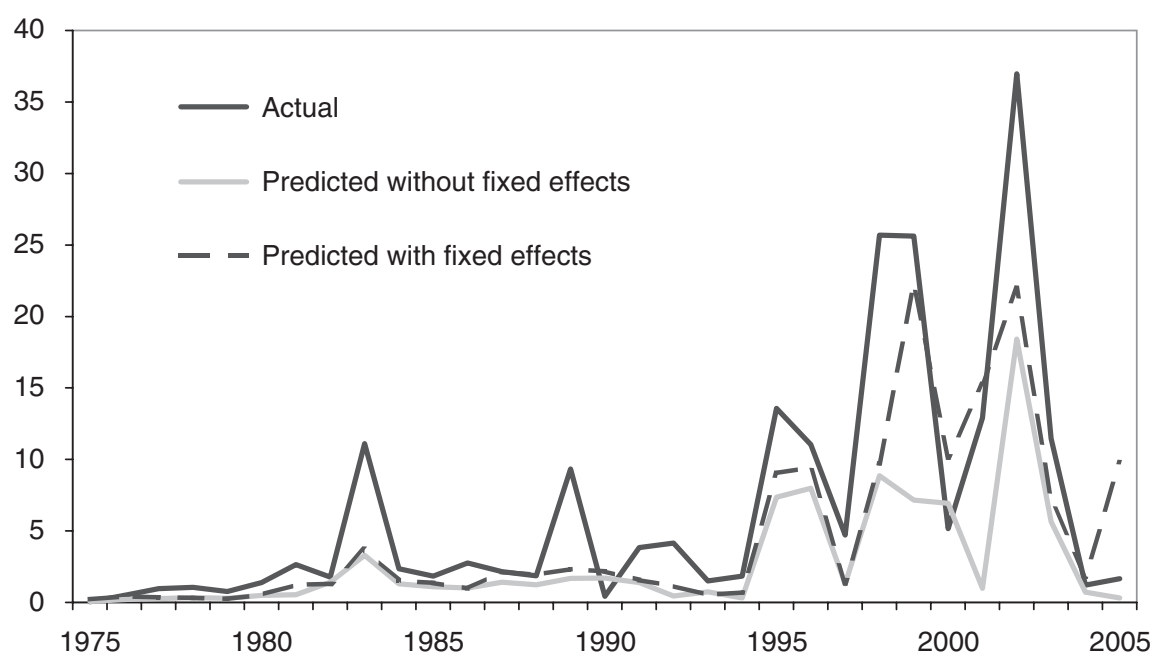

Sources: IMF, International Financial Statistics and World Economic Outlook databases; and authors' calculations.

Note: This figure presents the actual and predicted annual access levels of General Resources Account resources. The predicted values are based on Table 4 estimates and assume that a program was predicted to exist in the first stage of the proposed access model; that is, an IMF-supported program was predicted in the estimation of Table 1.

the model's mean prediction of aggregate access is SDR 6.6 billion compared with actual access during that period of SDR 14.3 billion. The major sources of error are that the model fails to predict two large programs (Colombia and Uruguay, which together total SDR 2.3 billion) and underestimates access in Argentina by about SDR 4 billion (Figure 5). ${ }^{25}$ This mean prediction assumes that the member has a program when the predicted probability exceeds the threshold - which, as discussed above, may be legitimate when considering the aggregate portfolio, though not for individual predictions. Using the point estimates of the probabilities instead yields an even lower estimate of about SDR 3.5 billion for 2003-05 because some of the highaccess programs that were realized receive a low probability weight (albeit, of course, higher than the threshold probability).

\section{Medium-Term Projections}

The models developed in the preceding sections can be used to generate medium-term projections of use of IMF resources. Such projections require forecasts of the explanatory variables; for most variables, country teams'

\footnotetext{
${ }^{25}$ See caveat regarding the interpretation of predictions for individual programs earlier in this section.
} 
WEO forecasts are used - the exceptions being the corporate bond yield and IMF quota, which are kept constant at their mid-2006 values. It bears emphasizing, however, that the projections of aggregate UFR will be only as good as the underlying forecasts of the explanatory variables. Indeed, there are several sources of uncertainty inherent in the projections of aggregate UFR. First, within each model, even conditional on the forecasts of the explanatory variables, the regressions have residuals - with zero mean and variance given by the standard error of the regression. Second, as noted, there is uncertainty surrounding the forecasts of the explanatory variables. Third, the model used for the projections may be fundamentally misspecified. Finally, although the models are estimated on the use of IMF resources, it is possible that members' response to balance of payments difficulties has shifted over time. In particular, recent developments in self-insurance and regional reserve pooling may provide an alternative to use of IMF resources.

To address the first of these sources of uncertainty, the baseline projections reported below include 90 percent confidence bands, derived by stochastic simulations using bootstrapping techniques (the entire probability distribution of GRA credit outstanding is shown as well). Thus, conditional on the explanatory variables, the probability of aggregate UFR being higher (lower) than the upper (lower) band is less than 5 percent.

Addressing the second source of uncertainty-forecast errors in the explanatory variables - is more tricky. A number of earlier studies have found that - with the exception of forecasts for advanced economies-WEO projections typically exhibit some optimistic bias, especially regarding variables such as output growth or external debt ratios. ${ }^{26}$ This would imply a downward bias in projections of the likelihood of a country needing IMF support and hence of aggregate use of IMF resources. Therefore, in one of the alternative scenarios considered below, a correction (based on historically observed WEO projection biases) is applied to the forecasts of the explanatory variables. A further difficulty is that country teams' WEO projections may represent the average of a bimodal forecast-good and bad scenarios; unfortunately, the WEO provides only country teams' central projections, not the distribution of those projections. To the extent that there are threshold effects in the determinants of balance of payments problems (although the estimated model does not exhibit such threshold effects), the use of the central forecasts could lead to an incorrect forecast of UFR. ${ }^{27}$

\footnotetext{
${ }^{26}$ IMF (2005a), which examined biases in IMF staff projections of debt, found that external debt-to-GDP ratios were underprojected by almost 1 percent over the one-year horizon, rising to 3 percent in the three-year-ahead projections. To this bias, lower-thanprojected GDP growth contributed $1 / 2$ percent at a one-year horizon, rising to $2 \frac{1}{2}$ percent over five years.

${ }^{27}$ For instance, suppose there is a threshold effect whereby a balance of payments problem (and thus a need for UFR) is more likely once the current account deficit exceeds 5 percent of GDP. Suppose, further, that the country team has a bimodal forecast for the current account balance of +5 percent of GDP (with 0.5 probability) and -5 percent probability (with 0.5 probability)-yielding an average projection for the current account
} 
Finally, the risk that the model is fundamentally misspecified is the most difficult to deal with, but it is somewhat mitigated here by the use of two distinct approaches - the time-series aggregate UFR model and the individual members' program and access model. Nevertheless, these various sources of possible error imply that any projections of aggregate use of IMF resources will be subject to a high degree of uncertainty.

\section{Baseline Projection}

The time-series model suggests that the end-2006 stock of IMF credit outstanding of SDR 10.6 billion is well below the level implied by the longrun relationship of SDR 24 billion (Figure 6, top panel). However, given expected declines in middle-income countries' external debt ratios and rising reserves coverage of short-term debt, the implied long-run value of IMF credit itself declines to SDR 16.5 billion by 2010. Meanwhile, short-run dynamics lead the stock of IMF credit to increase from the 2006 level and converge toward the 2010 long-run value. Thus, the time-series model predicts that the outstanding stock of IMF credit should reach SDR 10 billion by 2010, with the 90 percent confidence interval (based on the regression's residuals) ranging from SDR 6.8 billion to SDR 13 billion. Over 2006-10, IMF credit outstanding would average SDR 8.6 billion.

Turning to the "program selection and access" model, and again applying WEO projections but now for each individual country separately, the model predicts an average of 26 new arrangements over 2006-10, of which three would be "exceptional access" programs with systemically large, heavily indebted members. ${ }^{28}$ To generate these projections, the program selection logit is used to generate the probability that the member will have a program. Based on those probabilities, 1,000 stochastic simulations using a binomial random generator are carried out to determine whether a country has a program and the associated level of access. In turn, the level of access if a program exists has a country-specific shock based on bootstrapped errors from the access regression. Both the program selection logit and the access model simulations are carried out without country fixed effects. Instead, the access model includes a dummy variable for high-access countries (that is, large countries with high debt ratios), which serves to control for the

deficit of 0 percent of GDP. Because this is less than the threshold of -5 percent of GDP, the likelihood of a program is underestimated. However, threshold effects are not apparent in the model estimated above; moreover, it is not clear in which direction the results would be biased if threshold effects were present. If, for example, there is an appreciably lower likelihood of a crisis when reserves exceed a threshold of 100 percent of short-term debt, and the team's average projection was for reserves to be less than 100 percent of short-term debt (but the upper mode was more than 100 percent of short-term debt), then the model would overestimate the likelihood of a crisis.

${ }^{28}$ Predicted in the sense that the implied probability is greater than the sample frequency of 20 percent. However, arrangements are assumed to last two years; thus, the model cannot predict arrangements for the same member in two consecutive years. 


\section{Figure 6. Medium-Term Projections of IMF Credit Outstanding (In billions of SDRs; General Resources Account only)}
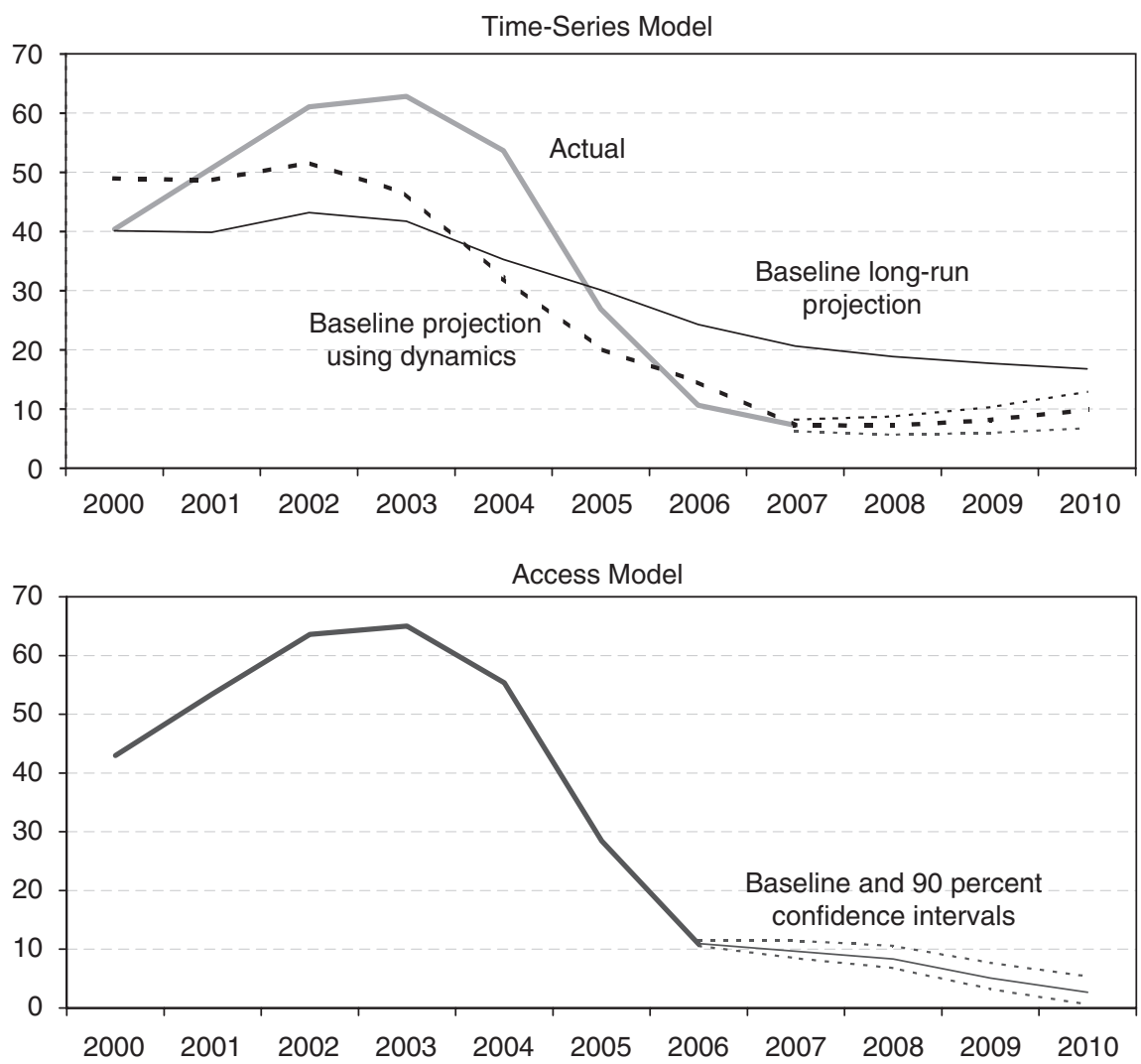

Sources: IMF, International Financial Statistics and World Economic Outlook databases; and authors' calculations.

Note: The baseline projections of the times-series model include 90 percent confidence bands derived by stochastic simulations using bootstrapping techniques. The baseline projections of the access model are calculated in three stages. First, the program selection logit is used to generate the probability that the member will have a program. Based on these probabilities, 1,000 stochastic simulations using a binomial random generator are carried out to determine whether a country has a program, and the associated level of access. Second, the level of access (if a program exists) has a country-specific shock based on bootstrapped errors from the access regression (these too are subjected to 1,000 rounds). Finally, the outstanding IMF resources are calculated using a bottomup approach. The underlying assumptions for this stage include: (1) 75 percent of all approved resources are disbursed over the following two-year period (i.e., 25 percent of the total in the year of approval and 50 percent in the following year; 75 percent is the historical disbursement average of IMF arrangements); (2) each disbursement has an average grace period of two years and a repayment period of four years; (3) similar disbursement and repayment profiles are applied to existing IMF arrangements; and (4) no early repayments take place beyond those announced as of end-2006. Ninety percent confidence intervals are added as dotted lines to the access model chart; the projection period is $2006-10$. 
conditions that could result in a capital account crisis (thus requiring high access to IMF resources). Although the profile of IMF credit outstanding is a bit different from the time-series model, the average level of UFR over 2006-10 is only marginally lower (around SDR 7.3 billion; Figure 6, bottom panel). ${ }^{29}$ Figure 7 depicts the entire probability density function for each year's outstanding UFR as projected by the two approaches in this paper. ${ }^{30}$ The 5 percent tails of these density functions correspond to the 90 percent confidence intervals depicted in Figure $6 .{ }^{31}$ As a robustness check, a partially observed bivariate model was estimated as an alternative to the first stage; in principle, this enables better taking into account the simultaneous decision by two agents - the country and the IMF-whether to have an IMF-supported program, though no identifying restrictions are imposed. As Maddala (1983, p. 282) notes, it is still possible to estimate such a partially observed bivariate model, but doing so typically does not produce good parameter estimates. This estimation (not reported) provides only marginally larger average levels of UFR over 2006-10 and with wider confidence bands. ${ }^{32}$

\section{Scenario Analysis}

It is useful to complement these baseline projections with scenario analysis in order to gauge the sensitivity of the results to specific assumptions. The first scenario applies a correction to the WEO forecasts of the explanatory variables based on historically observed biases-the most important being that the external debt ratio is typically underpredicted.

\footnotetext{
${ }^{29}$ Estimating the use of IMF resources by individual members over the same period used in the time-series model (1982-2005) provides similar results. Specifically, even though the number of observations declines by 20 percent, the coefficient estimates remain broadly unchanged (both in terms of significance and interpretation), and the aggregate use of IMF credit is only marginally different (SDR 7.5 billion instead of SDR 7.3 billion).

${ }^{30}$ Forecasts for the aggregate time-series model are obtained by Monte Carlo techniques, with residuals drawn randomly from a normal distribution with mean zero and standard deviation as implied by the regression estimates (1,000 rounds are used). Forecasts for the program selection and access model involve two steps: a binomial random generator with a mean equal to the probability of having an IMF-supported program is used in the stochastic probability simulations (1,000 rounds are used), and the estimated level of access is bootstrapped using country-specific errors from the access estimation (again, 1,000 rounds are used).

${ }^{31}$ The 90 percent confidence bands are asymmetric because no individual member's access and use of IMF resources can be negative. Hence, if outstanding credit is low, it is less likely to fall farther than it is to increase. This is more important for the model of individual members' program selection and access, the non-negativity constraint is more likely to be binding for an individual member than for the aggregate portfolio.

${ }^{32}$ The estimated bivariate probit model with partial observability follows Poirier (1980). Even though the projected UFR for 2010 is higher (about SDR 6 billion compared with SDR $3 \frac{1}{2}$ billion in the baseline), the confidence interval is much wider. Use of the bivariate probit method did not alter the significance of coefficients. However, owing to difficulties in convergence, richer identifying restrictions could not be applied.
} 
Figure 7. Stochastic Simulation of Outstanding IMF Credit, 2006-10 (General Resources Account only)
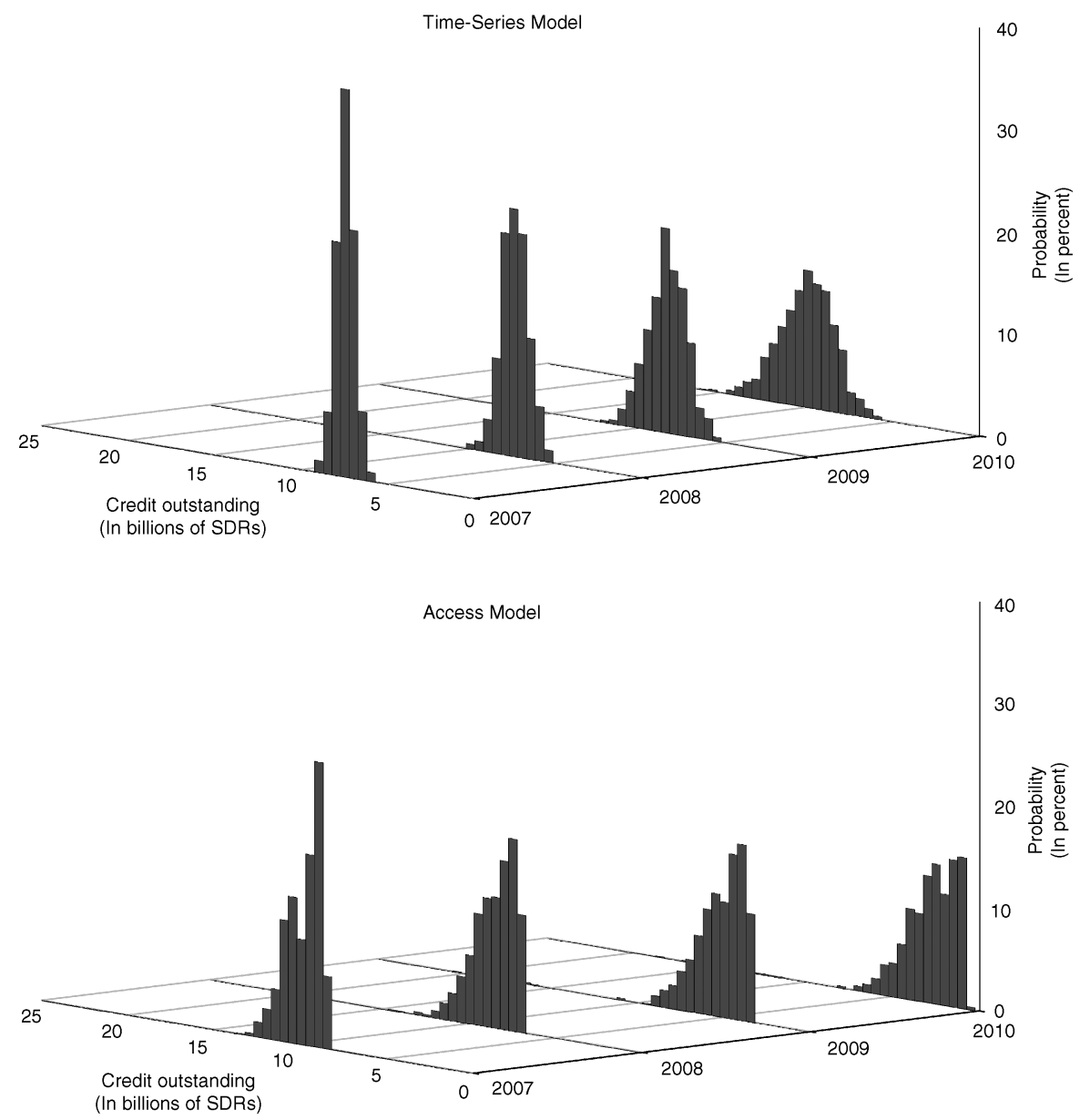

Sources: IMF; and authors' calculations.

Note: The methodology follows the description in Figure 6 (stochastic simulations using bootstrapping techniques) except that the entire probability distribution of General Resources Account credit outstanding is shown for both the time-series and the access model.

Although it does not necessarily follow that current WEO projections will exhibit the same optimistic bias as in the past, the impact on possible use of IMF credit is discernible. For instance, the time-series model's baseline prediction for aggregate UFR of SDR 8.6 billion averaged over the period 2006-10 becomes SDR 9.7 billion in this alternative scenario (Scenario I-A; Figure 8, top panel). A second scenario seeks to reproduce the conditions in the run-up to the 1997-98 Asian crisis. To this end, the same increase in the external debt and short-term debt-to-reserves 
Figure 8. Alternative Scenarios of IMF Credit Outstanding (In billions of SDRs; General Resources Account only)
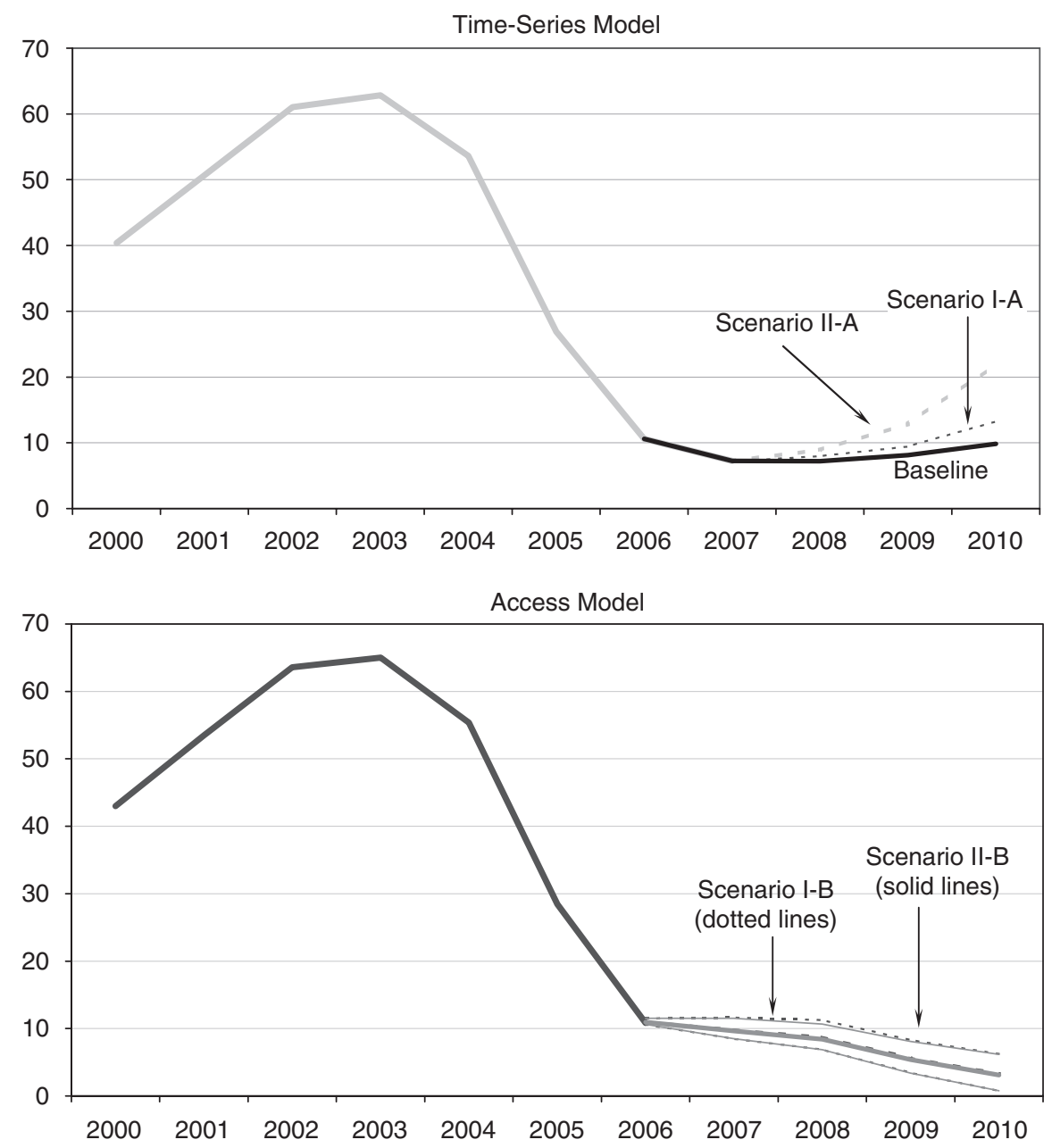

Sources: IMF, International Financial Statistics and World Economic Outlook databases; and authors' calculations.

Note: The methodology follows the description in Figure 6 (stochastic simulations using bootstrapping techniques) except that the baseline projections used in the forecasts are replaced by (1) Time-series model: Scenario I-A applies 1-year, 3-year, and 5-year ahead forecast errors to the projected World Economic Outlook (WEO) debt-to-GDP ratio. Scenario I-B applies 1-year, 3-year, and 5-year ahead forecast errors to all WEO forecasts for 2006-10; (2) Access model: Scenario II-A assumes that the increase in the total debt-to-GDP ratio and the ratio of short-term debt to reserves over the 5-year period prior to the Asian crisis is repeated in 2007 and 2008 and maintained through 2010. Scenario II-B assumes a two standard deviation shock in oil prices beginning in 2007. Ninety percent confidence intervals are added as dotted lines to the access model chart. 
ratio as experienced in the Asian crisis countries in 1994-96 is assumed to apply to all countries in the sample (and to persist over the forecast horizon). In this scenario, the predicted UFR rises to SDR 22 billion by 2010, with an average of SDR 12.3 billion for 2006-10 (Scenario II-A; Figure 8, top panel).

For the "program selection and access" model, applying the correction to WEO projections raises the average UFR prediction over the period 2006-10 from SDR 7.3 billion in the baseline to SDR 7.6 billion (Scenario I-B; Figure 8, bottom panel). In this scenario, the model predicts an average of 30 arrangements (of which five are exceptional access) over 2006-10, compared with an average of 26 new arrangements (of which three are exceptional access) in the baseline. The sensitivity of the results for use of IMF resources underscores the importance of realistic macroeconomic projections and debt sustainability analyses. Finally, another scenario considers the effects of a significant deterioration in global conditions - specifically, a two-standard-deviation shock to oil prices beginning in 2007 and maintained through 2010. Under this scenario, aggregate UFR would be expected to average SDR 8 billion over 2006-10, with much wider confidence bands (Scenario II-B; Figure 8 , bottom panel) and only a handful of programs more than in the baseline.

\section{Conclusions}

This paper presents two approaches to modeling the use of IMF resources in order to gauge whether the recent decline in IMF credit outstanding represents a temporary phenomenon or a permanent shift owing to improved macroeconomic performance and increased resilience to shocks among middle-income member countries. The two approaches, based, respectively, on the time-series behavior of aggregate IMF credit outstanding and on a two-stage "program selection and access" model, yield the same conclusion: there appears to be a fundamental shift in the use of IMF resources. Specifically, against an average GRA credit outstanding (to middle-income countries) of about SDR 50 billion over 2000-05, GRA credit outstanding is projected to average SDR 8 billion over the next five years - with stochastic simulations suggesting that it is unlikely to be much higher.

The projected decline in the aggregate use of IMF resources can be decomposed into two parts: a return to more normal levels of lending, given "fundamentals" (that is, the explanatory variables in the models), and the projected shift in fundamentals. First, the period from 2000-05 entailed exceptionally high use of IMF resources, with actual credit outstanding averaging some SDR 50 billion against the predicted level of some SDR 2540 billion (under the "program selection and access" model and the timeseries model, respectively). Second, on the basis of projections of the explanatory variables, the predicted level of IMF credit outstanding falls 
from SDR 25-40 billion in 2000-05 to about SDR 8 billion (under either model) over 2006-10. Moreover, these projections assume a stable relationship between fundamentals and use of IMF resources. To the extent that there has been a shift in members' preferences away from seeking the IMF's support - and this shift has not been manifested in improved macroeconomic performance and resilience to shocks - aggregate use of IMF resources could be even lower.

There are, however, important methodological caveats to the analysis. In particular, forecasts of UFR are conditional on the underlying forecasts of macroeconomic performance of middle-income countries (especially dynamics of external debt and reserves). To the extent that projections of economic performance reflect a continuation of the current exceptionally benign global economic conditions, it is natural to expect that the use of IMF resources will remain at the currently low levels. To assess the robustness of the results, their sensitivity to alternative assumptions is examined using scenario analysis. For example, if current WEO projections turn out to have the same degree of overoptimism as in the past, then use of IMF credit outstanding would be projected to average about SDR 8-9 billion over the next five years.

More generally, it is of course possible that a confluence of unexpected adverse factors will trigger future balance of payments needs, perhaps in several countries simultaneously owing to contagion. Nevertheless, the analysis presented here, although preliminary, suggests that use of IMF resources over the next few years is likely to be considerably lower than in the recent past.

\section{APPENDIX I}

\section{Is There a Nonlinear Process in the Demand for UFR?}

As noted in the main text, the time-series model assumes a single stochastic process driving the use of IMF resources over the past 25 years. Yet the structure of the portfolio has evolved over time, and there are clearly periods - such as the early 1980s and the mid1990 s - when there was more intense lending activity.

This appendix therefore considers whether aggregate UFR can be better described by multiple processes, and what determines the transition across process. For this purpose, Markov switching models, as developed in the economics literature by Hamilton (1989) and Filardo and Gordon (1998) are a useful tool, because they can identify discontinuities in the data-generating process, by modeling permanent regime changes owing to structural shifts as well as extraordinary short-period events. ${ }^{33}$ Moreover, in contrast to simple event studies, the endogenous selection mechanism obviates the need for any a priori identification of the regime or the timing of switches across regimes.

\footnotetext{
${ }^{33}$ See Goretti (2005) for an application of an endogenous Markov-switching model to Brazil in 2002.
} 
A simple multivariate specification, with a state-dependent shift in mean and two states - a low-lending regime and a high-lending regime - is adopted. ${ }^{34}$ The use of a timevarying transition probability allows the model to incorporate economic variables in determining when a regime switch occurs; the variable used here is an exchange market pressure (EMP) index. The model equations are:

$$
\begin{aligned}
& U F R_{t}=\alpha_{0}+\alpha_{1} S_{t}+\beta^{\prime} x_{t}+\varepsilon_{t}, \quad \varepsilon_{t} \sim N\left(0, \sigma^{2}\right), \\
& \operatorname{Pr}\left\{S_{t}=1\right\}=\operatorname{Pr}\left\{S_{t}^{*} \geq 0\right\}, \\
& S_{t}^{*}=\gamma_{0}+\gamma_{1} S_{t-1}+\delta^{\prime} E M P_{t-1}+u_{t} .
\end{aligned}
$$

The use of IMF resources is modeled in the measurement equation. The transition probability is estimated by means of a probit model, where the latent variable $S *$ depends on the previous state but also on lagged values of the EMP index.

The country sample is the same as that used in the main text, but a longer time series and quarterly data are used. For the purpose of the analysis, we use aggregate cross-country time series at quarterly frequency over 1974-2005. The EMP index is defined as the average of changes in the nominal exchange rate, in the short-term interest rate, and in the international ratio of reserves to broad money, weighted by the variable respective volatility and benchmarked to the U.S. economy. Cross-country aggregation is obtained by weighting each country EMP index by its GDP weight in the sample group.

Estimates for the final specification of the above regime-switching equations suggest two significantly different states, characterized by a high- and a low-lending regime (Appendix Table A1). In particular, under the high-lending regime, use of IMF resources by this group of countries is almost 34 percent of GDP higher than in the low-lending state. In the measurement equation, use of IMF credit (in percent of GDP) is found to depend significantly, and with a negative sign, on changes in the current account balance, and on the corporate bond premium net of the IMF's rate of charge. ${ }^{35}$ Total external debt enters into the equation with a significant positive sign. Finally, the EMP index enters directly into the transition equation, proving to have a significant positive effect on the regime latent variable, which underlines the evident link between crisis probability and access to IMF lending, and the proportionality between the extent of market pressure and the need for exceptional lending programs.

The $R^{2}$ for the regression indicates that the selected explanatory variables account for almost 60 percent of the variation in aggregate IMF credit outstanding. Although the explanatory power of the Markov switching specification could be further improved, it

\footnotetext{
${ }^{34}$ The test for nonlinearity in UFR follows the non-parametric test developed by Luukkonen, Saikkonen, and Teräsvirta (1988) and Teräsvirta (1994). The test is a Lagrange multiplier test for a third-order Taylor approximation to the univariate regression and allows identification of general nonlinearity through the significance of the higher-order terms. The main advantage of this type of test is that it can be carried out by simple ordinary least squares (OLS) and that it is sensitive to a wide range of nonlinearities. The results of this test are reported in Table 1 and show significant evidence of nonlinearity in the series.

${ }^{35}$ Note that the negative sign for the reserve coverage regressor (which already excludes China), although significant, may reflect the almost exponential upward trend in aggregate reserves for this group of countries; in all likelihood this reflects large reserve accumulation in other Asian countries.
} 
Table A1. Determinants of Use of IMF Resources Under Switching Regimes

\begin{tabular}{|c|c|c|c|c|c|}
\hline \multirow[b]{2}{*}{$\begin{array}{l}\text { Dependent Variable: } \\
\text { Access Amount as } \\
\text { Percent of GDP }\end{array}$} & \multicolumn{2}{|c|}{ Measurement Equation } & & \multicolumn{2}{|c|}{ Transition Equation } \\
\hline & Coefficient & $\begin{array}{c}\text { Standard } \\
\text { errors }\end{array}$ & & Coefficient & $\begin{array}{c}\text { Standard } \\
\text { errors }\end{array}$ \\
\hline $\begin{array}{l}\text { Constant under IMF } \\
\text { low-lending regime } \\
(\text { State }=0)\end{array}$ & $-9.28 *$ & 5.03 & Constant & $-1.60 * * *$ & 0.04 \\
\hline $\begin{array}{l}\text { Constant under IMF } \\
\text { high-lending regime } \\
(\text { State }=1)\end{array}$ & $43.02 * * *$ & 5.06 & Lagged EMP & $0.41 * * *$ & 0.08 \\
\hline $\begin{array}{l}\text { Change in current } \\
\text { account/GDP; lagged }\end{array}$ & $-291.92 * * *$ & 71.14 & Previous state & $2.50 * * *$ & 0.17 \\
\hline $\begin{array}{l}\text { Corporate bond premium } \\
\text { minus IMF's rate of } \\
\text { charge; lagged }\end{array}$ & $1.15 * * *$ & 0.35 & & & \\
\hline Term structure; lagged & -0.89 & 0.75 & & & \\
\hline $\begin{array}{l}\text { Total external debt/GDP; } \\
\text { lagged }\end{array}$ & $101.53^{* * *}$ & 19.22 & & & \\
\hline Reserve cover; lagged & $-7.29 * * *$ & 2.46 & & & \\
\hline Number of observations & 127 & & & & \\
\hline$R^{2}$ & 0.58 & & & & \\
\hline Adjusted $R^{2}$ & 0.55 & & & & \\
\hline $\begin{array}{l}\text { Teräsvirta linearity test } \\
\text { for UFR (delay=1; } \\
\mathrm{F}(3,134))\end{array}$ & $14.99 * * *$ & & & & \\
\hline Linear model fit: $R^{2}$ & 0.28 & & & & \\
\hline $\begin{array}{l}\text { Linear model fit: } \\
\quad \text { Adjusted } R^{2}\end{array}$ & 0.24 & & & & \\
\hline
\end{tabular}

Sources: IMF; and authors' calculations.

Note: This table presents estimates of the Markov switching model of access to IMF resources as percent of GDP described in this appendix. The transition probabilities are timevarying and endogenously estimated using the Gibbs sampler and assuming diffuse priors. The analysis is based on aggregate cross-country time series at quarterly frequency over 1974-2005 and includes countries that have borrowed from the IMF during that period except advanced economies and those that currently borrow from concessional facilities. The specification follows as closely as possible the linear time-series model reported in Table 1; any difference is due to the different data availability at quarterly frequency. The transition equation includes the lagged value of the exchange market pressure (EMP) index as an exogenous variable; the index includes changes in the nominal exchange rate, short-term interest rate, and foreign exchange reserves to broad money, weighted by the variable respective volatility. Crosscountry aggregation weights each country's EMP index by its GDP weight in the sample group. ${ }^{* *}, * *$, and $*$ denote significance at the 1,5 , and 10 percent levels, respectively. 
Figure A1. Demand for Use of IMF Resources (In percent of GDP; actual versus fitted data)

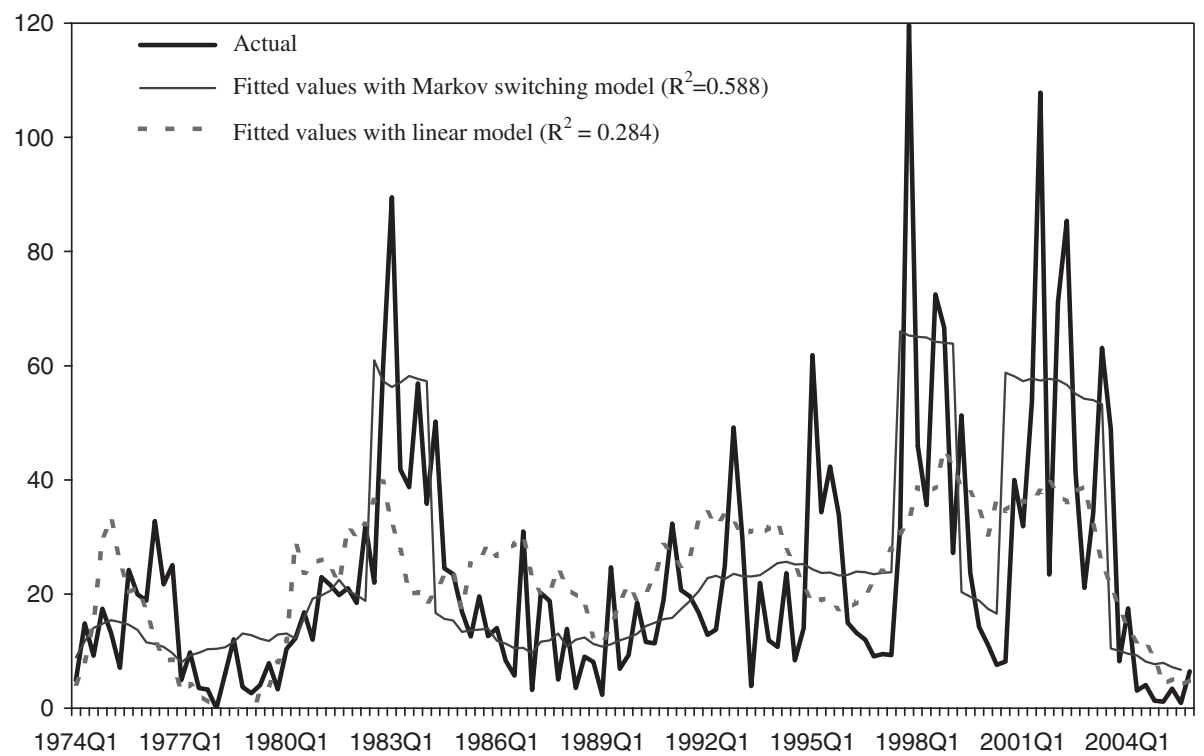

Sources: IMF; and authors' calculations.

Note: This figure presents the actual and predicted annual access levels to IMF resources as percentage of GDP. The predicted values are based on Appendix Table Al estimates. For comparison purposes, the figure also reports the access levels predicted using a linear OLS model with the same specification.

Figure A2. Use of IMF Credit: Smooth Probability of High-Lending Regime

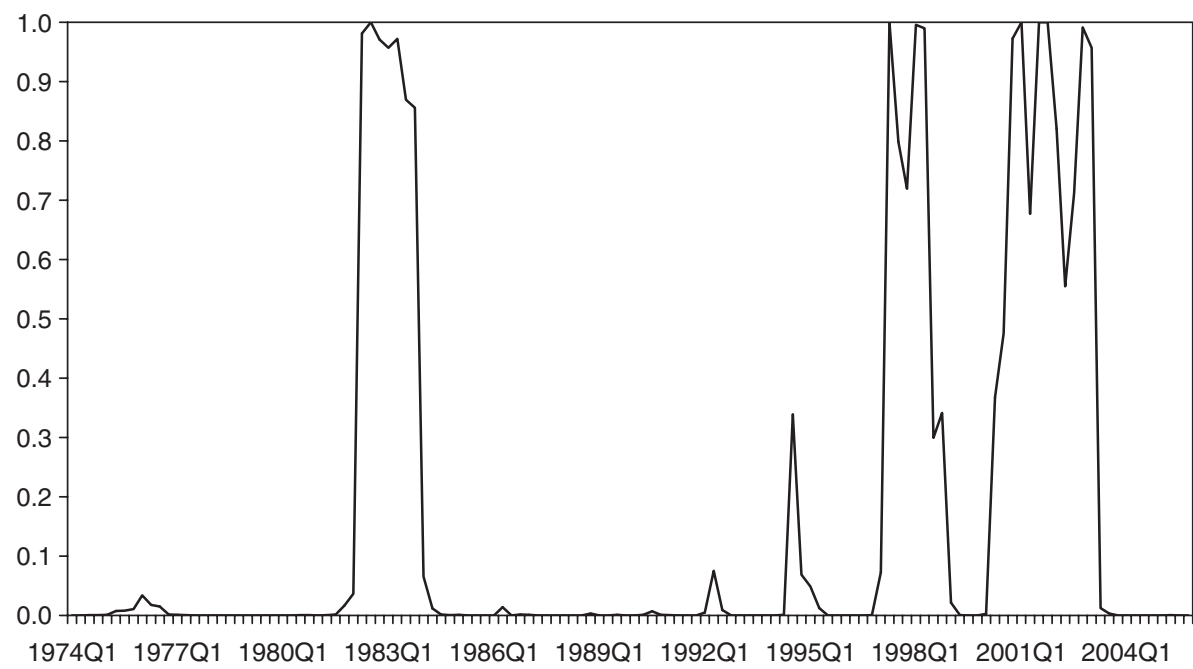

Sources: IMF; and authors' calculations.

Note: This figure presents the smooth probability of an IMF high-lending regime. The predicted values are based on Appendix Table A1 estimates of the transition equation. 
does outperform the estimates of a simple time-series model, as illustrated in Appendix Figure A1. Fitted values from the simple (linear) time-series model tend to average out the high-lending and low-lending processes, failing to capture the evident nonlinearity in the data. The nonlinear model is able to identify the main regime shifts in the series. In particular, the smooth probability of an IMF high-lending regime recognizes the peaks in the use of IMF resources during the major crisis episodes over the sample period (Appendix Figure A2).

These results suggest a need for caution in using only simple linear time-series methods - though the Markov switching model of the type used here is of limited use in projecting future use of IMF resources, because it is difficult to forecast which statehigh- or low-lending - will prevail. ${ }^{36}$ For this reason, the main text uses a simple linear time-series model - but supplements this analysis with a two-stage program selection logit and access regression.

\section{APPENDIX \|}

\section{Demand for IMF Resources—Literature Survey}

Although the literature on aggregate use of IMF resources is nascent, there are a number of studies that examine the economic and political determinants of a member having an IMF-supported program (see Appendix Table B1). Most studies examine a large number of economic and political variables in the context of various econometric models, including limited dependent variable models and ordinary least squares (OLS) regressions on both pooled and panel data. ${ }^{37} \mathrm{~A}$ few papers use case studies or descriptive statistics to try to draw conclusions about the factors leading to demand for IMF credit. The results of the range of studies show, however, that only a few variables consistently emerge as statistically significant. Moreover, although some studies identify factors that increase the probability of a member country requesting an IMF-supported program, they are less successful at predicting actual access levels, owing in part to the increasing importance of capital account crises in outstanding IMF credit positions. Because capital account crises are rare events with many different triggers, it is difficult to identify empirical regularities.

\section{Global Factors}

Only a minority of studies included global environment factors. These included real or nominal industrial country interest rates, global GDP growth, commodity prices, ${ }^{38}$ and

\footnotetext{
${ }^{36}$ This model does provide probabilities of each state being realized (Appendix Figure A2). A specification that disaggregates UFR into regional components suggests that Asian countries are less likely to be in the high-lending state than Latin American countries. Historically, the only period in the sample during which the Asian economies had a high probability of being in the high-UFR state was in the mid-1990s.

${ }^{37}$ The OLS regressions use various measures of the demand for IMF credit, including new gross and net purchases (in millions of SDRs or as a share of GDP).

${ }^{38}$ Elekdag (2006) examines the effect of oil prices on the demand for IMF credit. That study finds a positive and significant relationship between oil prices and the probability of an IMF-supported program being approved. Joshi and Zalduendo (2006) extend the framework put forward by Elekdağ by using a two-stage procedure that allows estimation of country access after controlling for a country's decision to request a program. Specifically, the paper
} 
total outstanding IMF credit (generally interpreted as a measure of the IMF's budget constraint) among the explanatory variables, with mixed results.

\section{Country-Specific Factors}

Economic variables: Many studies find the level of reserves, generally measured by their coverage of imports, ${ }^{39}$ and the level of economic development of a country (measured by GNP per capita) to be negatively correlated with use of IMF credit at conventional significance levels. ${ }^{40}$ Several studies also find - though not always consistently-the current account and/or overall balance of payments position, GDP growth, external debt service, external debt, access to private financing, real exchange rate overvaluation, investment levels, and measures of public expenditure or fiscal deficits to be significant.

"Political" variables: a previous IMF arrangement is a powerful predictor of future IMF arrangements in some circumstances (the authors generally interpret a previous program as carrying a fixed political cost associated with a close relationship to the IMF, which, once incurred, makes governments less reluctant to request further IMF assistance). Some studies also identify political or economic alignment with the United States and the time until the next election as a factor.

\section{Drawbacks of Existing Studies}

The usefulness of these studies to help assess the future demand for IMF credit is limited, for a variety of reasons. First, the predictive power of the models appears to be very poor. Second, most of the studies do not cover the financial crises of the 1990s. Third, methodological and data frequency issues suggest that it is very difficult to estimate the demand for IMF credit with a reasonable degree of accuracy.

In most studies, the prediction accuracy is only marginally better than the naive prediction of always forecasting no program. Specifically, although the various models correctly project $80-90$ percent of total outcomes in in-sample forecasts of the demand for IMF credit, a simple guess of "no agreement" would typically be accurate about 80 percent of the time (see Bird and Rowlands, 2001). Out-ofsample forecasts are included in only three of the studies: (1) Bird (1995) found that his model could not be used for forecasting, and that studies based solely on country economic characteristics tended to overestimate the number of countries that will borrow from the IMF; (2) in contrast, preliminary results by Elekdağ

identifies factors that influence the decision to request a Stand-By Arrangement and, given that decision, examines the factors that determine program access levels. This paper also restricts the sample to Stand-By-Arrangement-type programs, thus addressing another methodological problem found in the literature. Nevertheless, given the rare-event nature of recent capital account crises cases, the model underpredicts actual demand for IMF resources frequently during the 1990s.

${ }^{39}$ There is evidence that the level of reserves may be a relevant factor only where the exchange rate is fixed.

${ }^{40}$ Only two studies (Bird, 1995; Marchesi, 2003) did not find reserves to be significant in their econometric models. Vreeland (2004), Marchesi (2003), Bird and Rowlands (2001), Thacker (1999), and Santaella (1996) did not find the level of economic development significant. Several other studies did not include a proxy for the level of economic development. 
(2006), using a comprehensive sample, indicate a projected number of five to six new Stand-By Arrangement approvals in 2004, compared with an actual realization of six; and (3) Joshi and Zalduendo (2006) find that the model has limited success in predicting access levels in the context of capital account crises, suggesting that these rare events are a source of uncertainty that needs to be understood better.

Most of the studies do not cover the second half of the 1990s and are therefore likely to miss important vulnerabilities associated with stock imbalances emerging in capital account crises. ${ }^{41}$ Furthermore, of those studies that do cover this period, several do not adjust their choice of economic variables to account for the fact that balance of payments needs in this period originated in the capital account; for instance, they still use the reserves-to-imports ratio (a current account concept) rather than the ratio of reserves to M2 or short-term debt (a capital account concept), even though the literature on early warning systems has shown that the latter is more appropriate whenthe purpose is to assess the likelihood of a capital account crises. ${ }^{42}$ Moreover, one of the more recent studies (Oatley and Yackee, 2000) uses dummy variables to account for the Asian and/or Russian crises, giving rise to a trivial association of the demand for IMF credit with the existence of financial crises, which is of no help in an exercise aimed at forecasting future demand.

In all but three of the studies surveyed, the analysis does not distinguish between the various types of IMF facilities. In most studies, the analysis is based on data for all types of IMF arrangements, even though the determinants of demand for IMF credit under a Stand-By Arrangement are likely to be quite different from those associated with longer-term facilities, including concessional ones. This intermingling of demand for IMF credit under the various facilities would make it difficult to use the results of these models to forecast future demand for IMF credit under the GRA alone.

Only four out of the 20 studies use the amount of IMF credit as a dependent variable (Bird, 1995; Oatley and Yackee, 2000; Dreher and Vaubel, 2004; and Barro and Lee, 2005). Most studies estimate the probability of approval of an arrangement in a limited dependent variable model. It is not clear that the two variables should be determined by the same set of explanatory factors. Although the probability of approval of an arrangement should be influenced by macroeconomic, structural, and political variables, the amounts of IMF credit should be a function of the agreed-on policy response to a crisis.

Related to this, the low frequency of the data used in all studies may create additional problems for projecting demand for IMF resources in financial crises. In these crises, balance sheet pressures tend to build quickly, and sometimes over much shorter horizons than 12 months, driven by sudden changes in investor sentiment and portfolio allocation. More broadly, the use of annual data makes it hard to distinguish between economic and political conditions prior to and after approval of an IMF arrangement when corrective policies start to be implemented.

\footnotetext{
${ }^{41}$ Only Barro and Lee (2005); Sturm, Berger, and de Haan (2005); Trudel (2005); Elekda ğ (2006); and Joshi and Zalduendo (2006) cover the period through at least 2000.

${ }^{42}$ For an overview of this literature, see Berg, Borensztein, and Patillo (2004).
} 


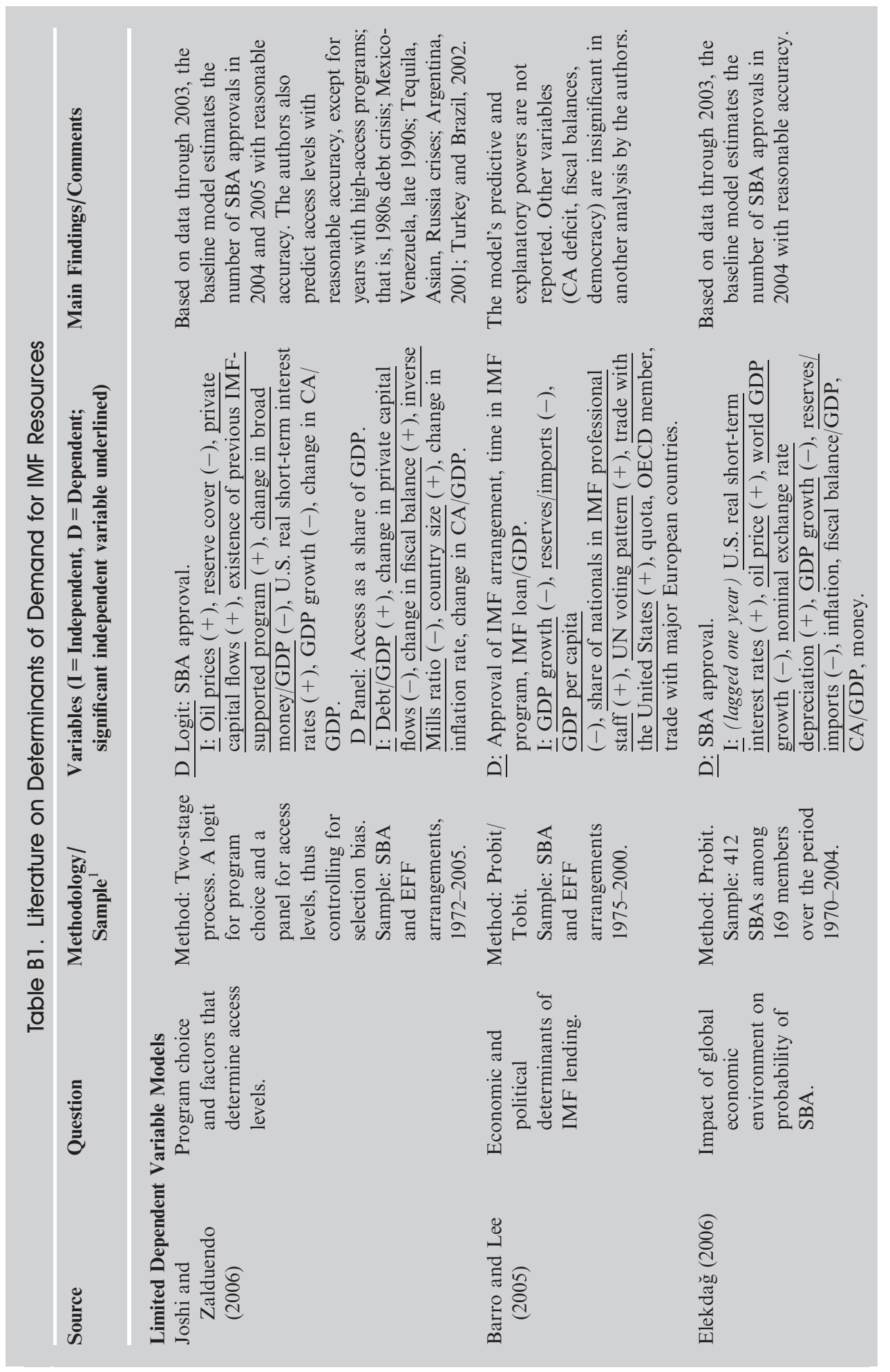




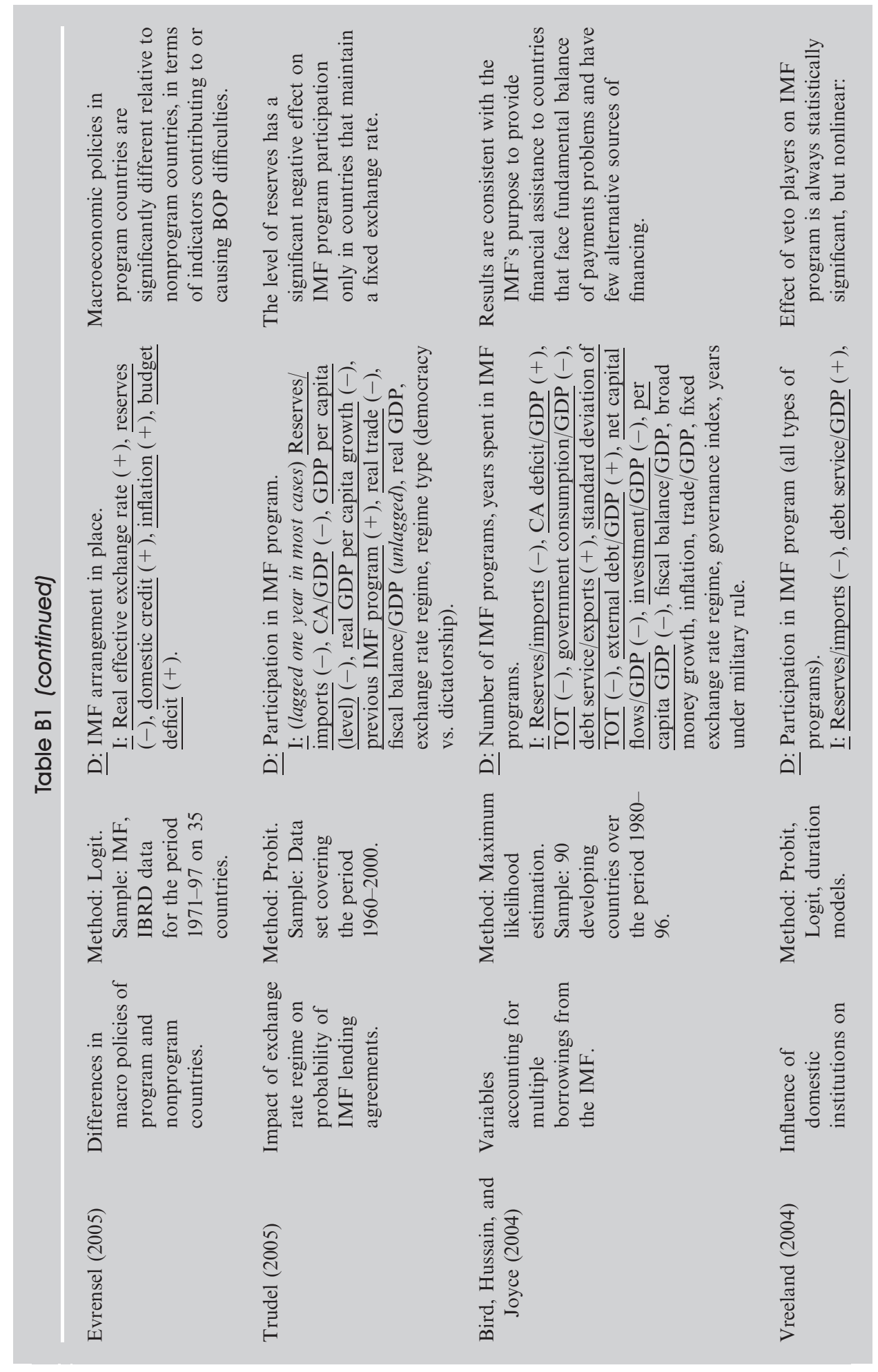




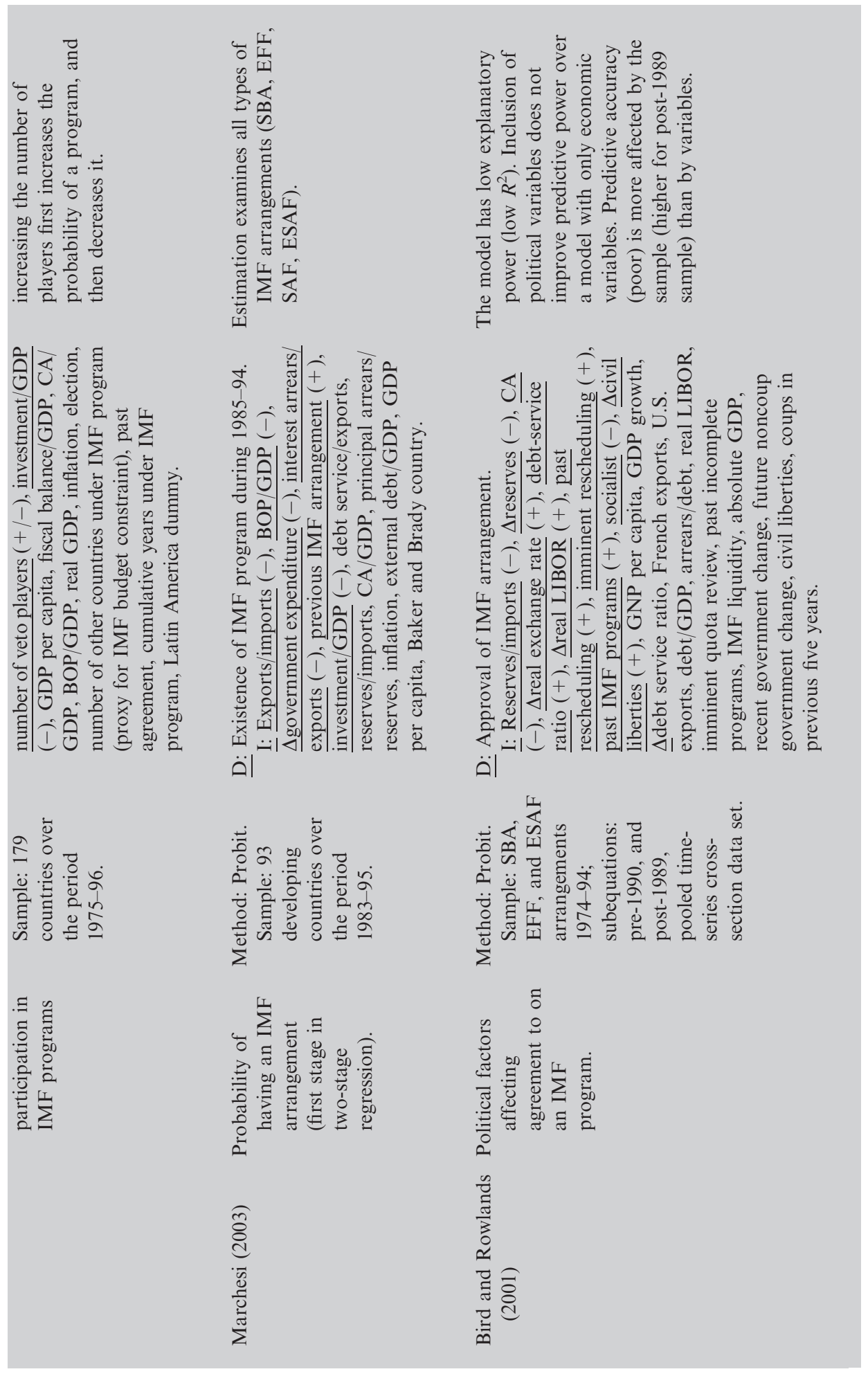




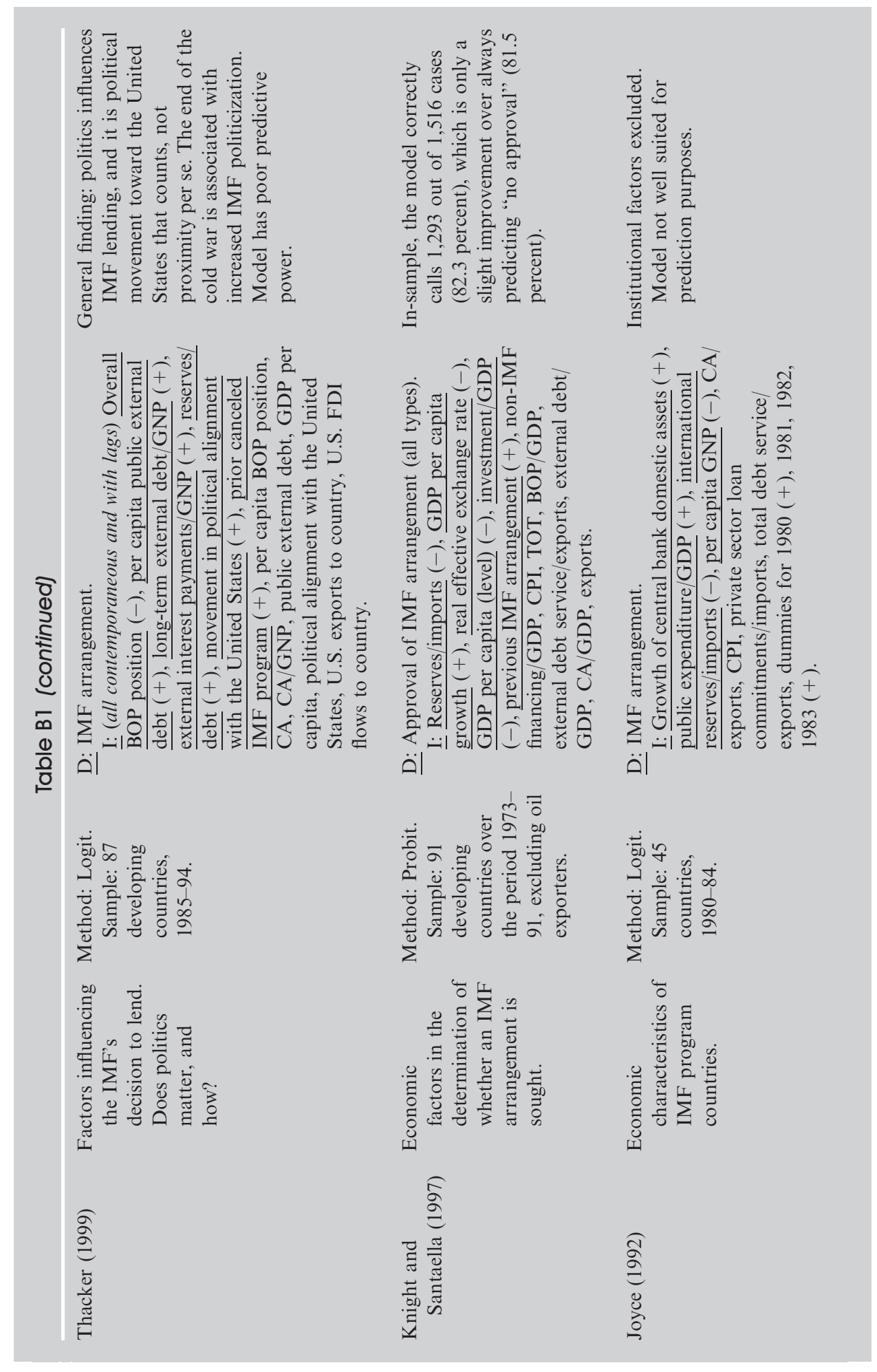




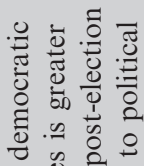

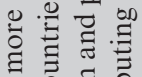

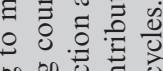

on on

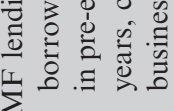

$\sum$

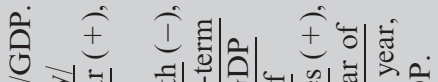

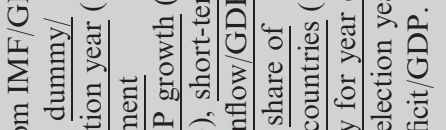

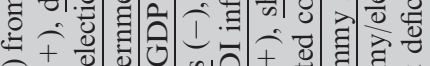

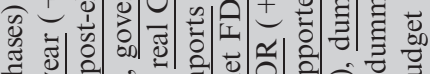

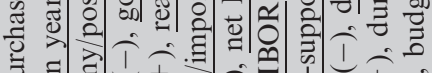

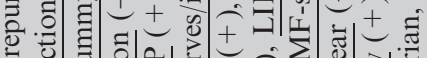

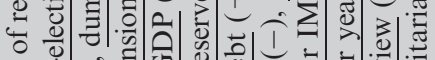

氙

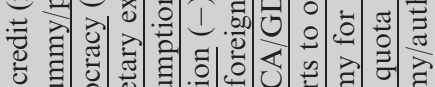

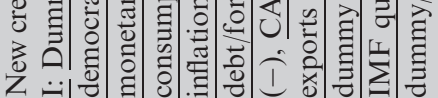

|

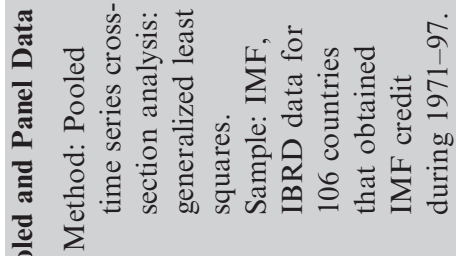

๕ั

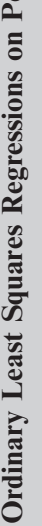

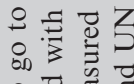

월

ॠ

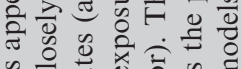

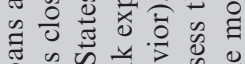

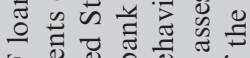

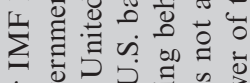

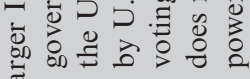

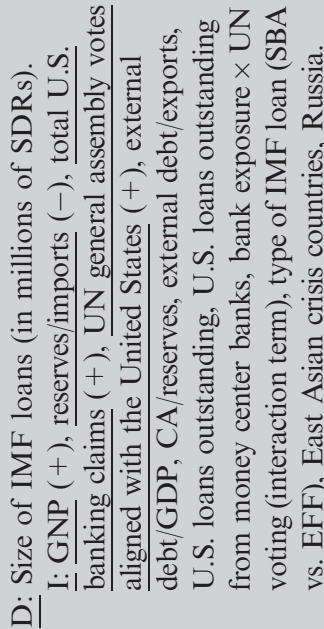

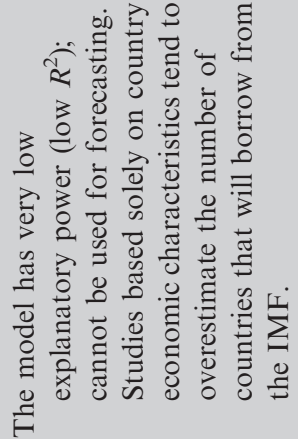

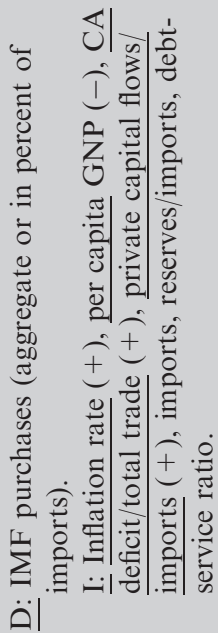

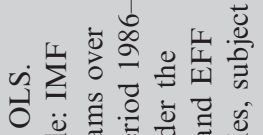

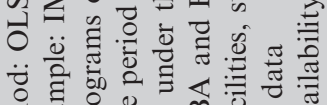

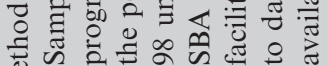

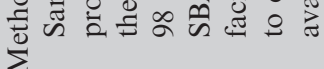
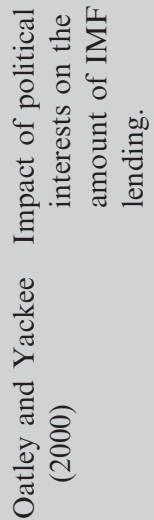
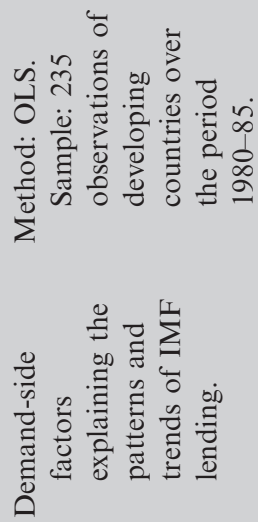


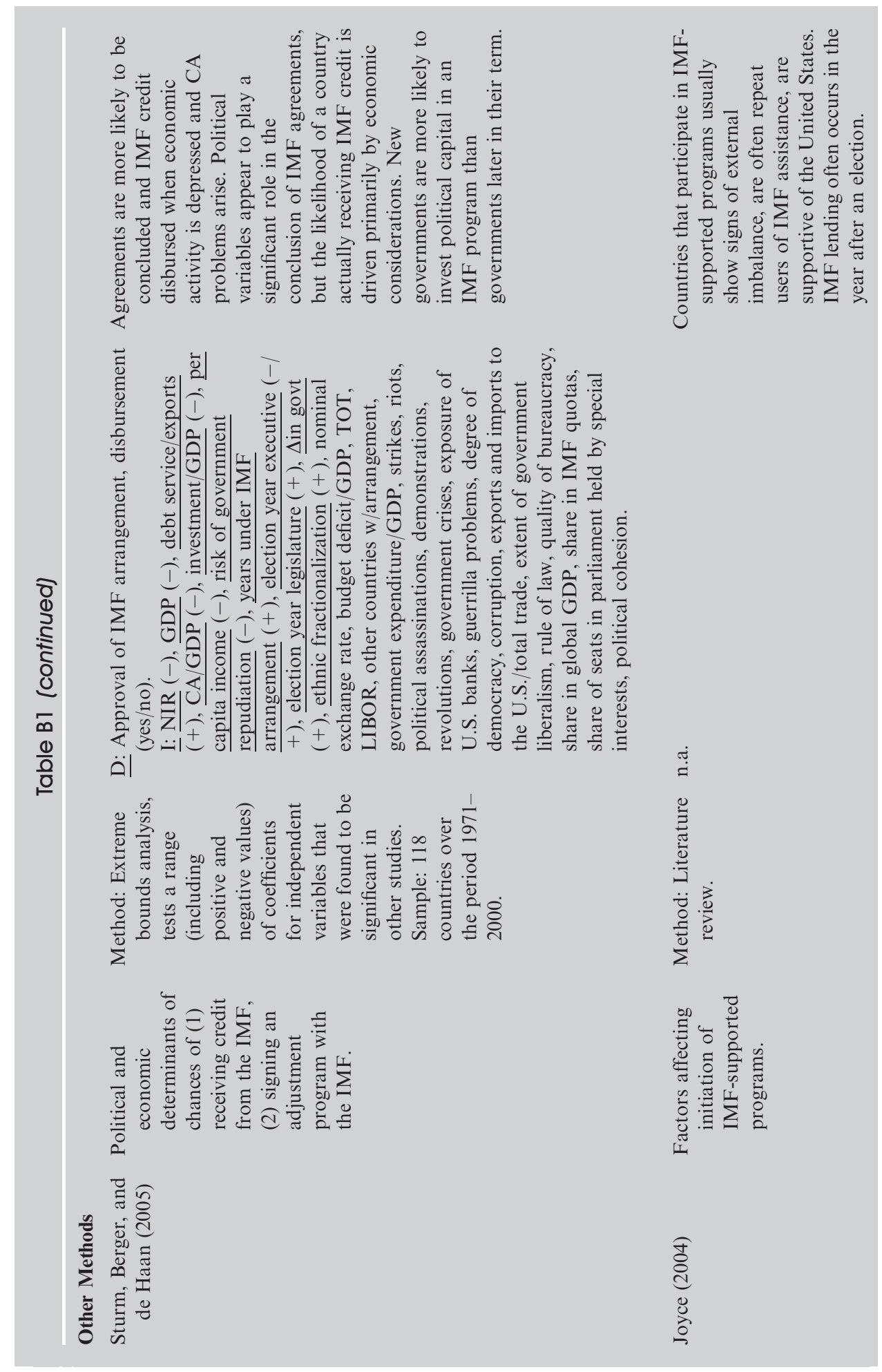



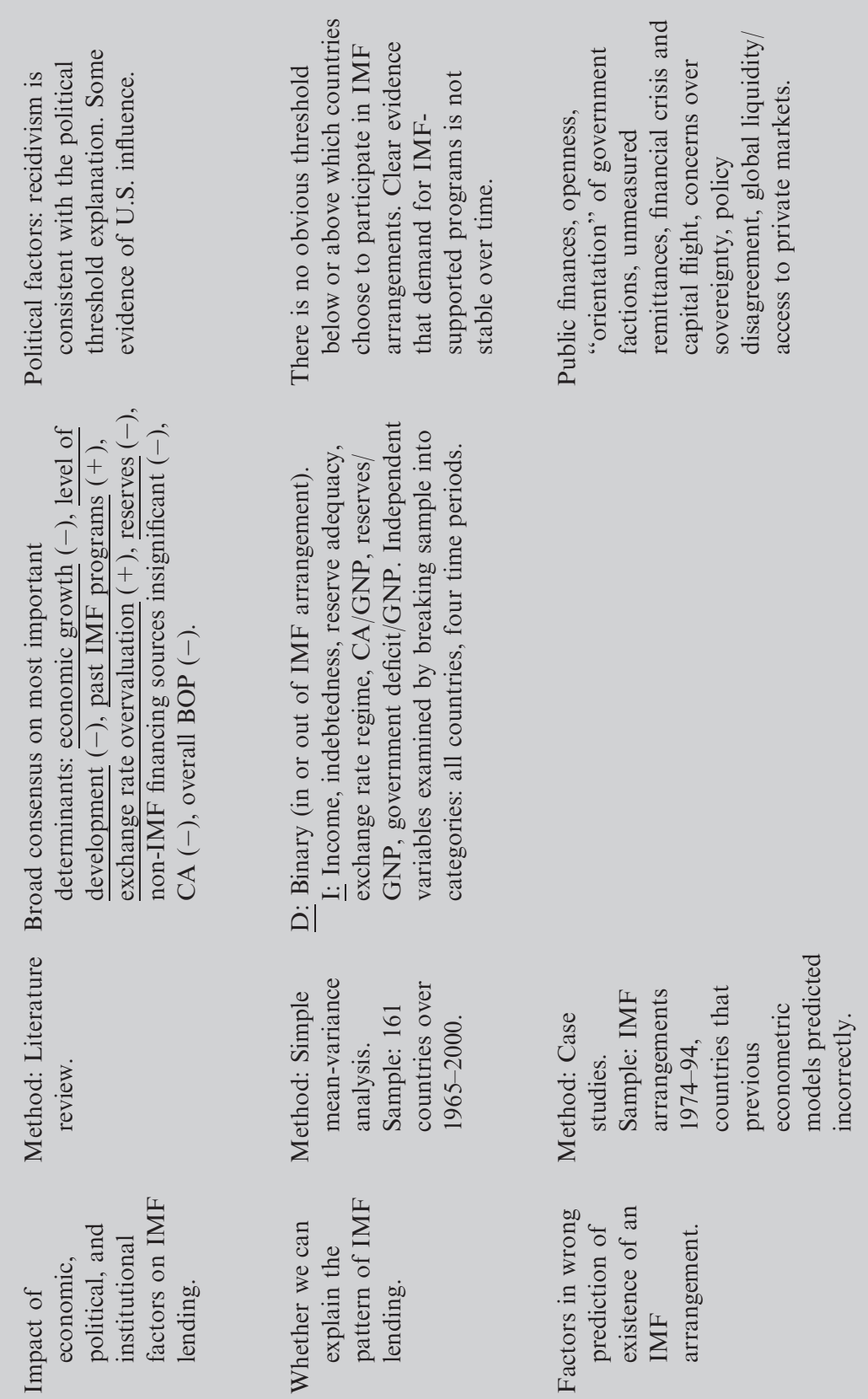

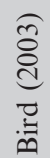
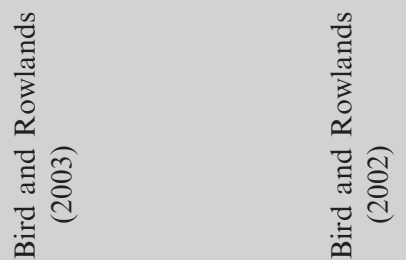


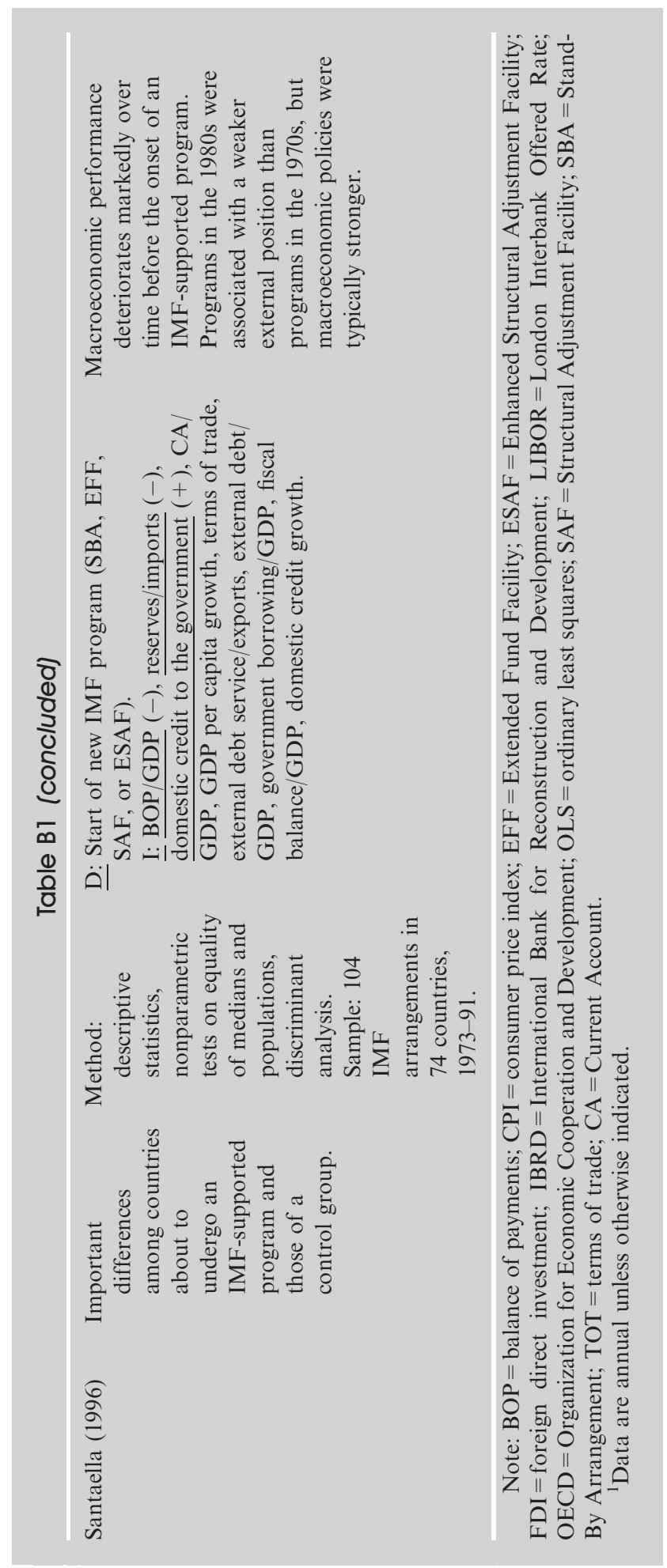




\section{REFERENCES}

Barro, Robert, and Jong-Wha Lee, 2005, "IMF Programs: Who Is Chosen and What Are the Effects," Journal of Monetary Economics, Vol. 52 (October), pp. 1245-69.

Berg, Andrew, Eduardo Borensztein, and Catherine Pattillo, 2004, "Assessing Early Warning Systems: How Have They Worked in Practice?," IMF Working Paper 04/52 (Washington, International Monetary Fund).

Bird, Graham, 1995, IMF Lending to Developing Countries: Issues and Evidence (New York, Routledge). 2003, The IMF and the Future: Issues and Options Facing the Fund (New York, Routledge).

Mumtaz Hussain, and Joseph P. Joyce, 2004, "Many Happy Returns? Recidivism and the IMF," Journal of International Money and Finance, Vol. 23 (March), pp. 231-51.

Bird, Graham, and Dane Rowlands, 2001, "IMF Lending: How Is It Affected by Economic, Political and Institutional Factors," Journal of Economic Policy Reform, Vol. 4, No. 3, pp. 243-70.

2002, "The Pattern of IMF Lending: An Analysis of Prediction Failures," Journal of Economic Policy Reform, Vol. 5, No. 3, pp. 173-86.

2003, "Can We Explain the Pattern of IMF Lending?," (unpublished; Surrey, University of Surrey). Available via the Internet: http://www.yale.edu/macmillan/ globalization/gbdryale.pdf.

Cerutti, Eugenio, 2007, "IMF Drawing Programs: Participation Determinants and Forecasting," IMF Working Paper 07/152 (Washington, International Monetary Fund).

Conway, Patrick, 2007, "The Revolving Door: Duration and Recidivism in IMF Programs," Review of Economics and Statistics, Vol. 89 (May), pp. 205-20.

Dreher, Axel, and Roland Vaubel, 2004, "Do IMF and IBRD Cause Moral Hazard and Political Business Cycles? Evidence from Panel Data," Open Economies Review, Vol. 15 (January), pp. 5-22.

Dubin, Jeffrey, and Daniel McFadden, 1984, “An Econometric Analysis of Residential Electric Appliance Holdings and Consumption," Econometrica, Vol. 52 (March), pp. $345-62$.

Elekdağ, Selim, 2006, "How Does the Global Economic Environment Influence the Demand for IMF Resources?" IMF Working Paper 06/239 (Washington, International Monetary Fund).

Estrella, Arturo, 1998, “A New Measure of Fit for Equations with Dichotomous Dependent Variables," Journal of Business and Economic Statistics, Vol. 16 (April), pp. 198-205.

Evrensel, Ayşe, 2005, "IMF Programmes in Emerging Countries," Comparative Economic Studies, Vol. 47 (March), pp. 4-22.

Filardo, Andrew, and Stephen Gordon, 1998, "Business Cycle Durations," Journal of Econometrics, Vol. 85 (July), pp. 99-123.

Ghosh, Atish, and others 2005, The Design of IMF-Supported Programs, IMF Occasional Paper No. 241 (Washington, International Monetary Fund).

Goretti, Manuela, 2005, "The Brazilian Currency Turmoil of 2002: A Nonlinear Analysis," International Journal of Finance and Economics, Vol. 10 (October), pp. 289-306.

Hamilton, James, 1989, “A New Approach to the Economic Analysis of Nonstationary Time Series and the Business Cycle," Econometrica, Vol. 57 (March), pp. 357-84. 
Heckman, James, 1979, "Sample Selection Bias as a Specification Error," Econometrica, Vol. 47 (January), pp. 153-61.

Horsefield, J. Keith, 1969, The International Monetary Fund, 1945-1965: Twenty Years of International Monetary Cooperation (Washington, International Monetary Fund).

International Monetary Fund (IMF), 2000, "Review of Fund Facilities-Proposed Decisions and Implementation Guidelines" (Washington). Available via the Internet: www.imf.org/external/np/pdr/fac/2000/02/index.htm.

2002, “Assessing Sustainability" (Washington). Available via the Internet: www.imf.org/external/np/pdr/sus/2002/eng/052802.pdf.

2003, "Access Policy in Capital Account Crises-Modifications to the Supplemental Reserve Facility (SRF) and Follow-up Issues Related to Exceptional Access Policy" (Washington). Available via the Internet: www.imf.org/external/np/ tre/access/2003/pdf/011403.pdf.

2005a, "Are Fund Staff Projections of Debt More Optimistic Under Program Contexts?" (Washington). Available via the Internet: www.imf.org/external/np/pp/ eng/2005/110905.pdf.

2005b, Selected Decisions and Selected Documents of the International Monetary Fund, Thirtieth Issue (Washington, International Monetary Fund).

2006, "Precautionary Arrangements: Purposes and Performance," (Washington). Available via the Internet: www.imf.org/external/np/pp/eng/2006/032306p.pdf.

Joshi, Bikas, and Atish Ghosh, 2003, "How Good (or Bad) Are Fund Projections?" (unpublished; Washington, International Monetary Fund).

and Juan Zalduendo, 2006, "A Note on Program Selection and Access Levels" (unpublished; Washington, International Monetary Fund).

Joyce, Joseph, 1992, "The Economic Characteristics of IMF Program Countries," Economics Letters, Vol. 38 (February), pp. 237-42.

2004, "Adoption, Implementation, and Impact of IMF Programmes: A Review of the Issues and Evidence," Comparative Economic Studies, Vol. 46 (September), pp. 451-67.

Knight, Malcolm, and Julio Santaella, 1997, "Economic Determinants of IMF Financial Arrangements," Journal of Development Economics, Vol. 54 (December), pp. 405-36.

Luukkonen, Ritva, Pentti Saikkonen, and Timo Teräsvirta, 1988, "Testing Linearity Against Smooth Transition Autoregressive Models," Biometrika, Vol. 75 (September), pp. 491-9.

Maddala, G.S., 1983, Limited Dependent and Qualitative Variables in Economics, Econometric Society Monograph (Cambridge, United Kingdom, Cambridge University Press).

Marchesi, Silvia, 2003, "Adoption of an IMF Programme and Debt Rescheduling: An Empirical Analysis," Journal of Development Economics, Vol. 70 (April), pp. 403-23.

Oatley, Thomas, and Jason Yackee, 2000, "Political Determinants of IMF Balance of Payments Lending: The Curse of Carabosse?" (unpublished; Chapel Hill, North Carolina, University of North Carolina). Available via the Internet: www.unc.edu/ $\sim$ toatley/imf.pdf.

Phillips, Peter, 1986, "Understanding Spurious Regressions in Econometrics," Journal of Econometrics, Vol. 33 (December), pp. 311-40.

Poirier, Dale, 1980, "Partial Observability in Bivariate Probit Models," Journal of Econometrics, Vol. 12 (February), pp. 209-17. 
Przeworski, Adam, and James Vreeland, 2000, "The Effect of IMF Programs on Economic Growth," Journal of Development Economics, Vol. 62 (August), pp. 385-421.

Royal Swedish Academy of Sciences, 2000, "The Scientific Contributions of James Heckman and Daniel McFadden," (Stockholm). Available via the Internet: nobelprize.org/nobel_prizes/economics/laureates/2000/ecoadv.pdf.

Santaella, Julio, 1996, "Stylized Facts Before IMF-Supported Macroeconomic Adjustment," IMF Staff Papers, Vol. 43 (September), pp. 502-44.

Sturm, Jan-Egbert, Helge Berger, and Jakob de Haan, 2005, "Which Variables Explain Decisions on IMF Credit? An Extreme Bounds Analysis," Economics and Politics, Vol. 17 (July), pp. 177-13.

Teräsvirta, Timo, 1994, "Specification, Estimation, and Evaluation of Smooth Transition Autoregressive Models," Journal of the American Statistical Association, Vol. 89 (March), pp. 208-18.

Thacker, Strom, 1999, "The High Politics of IMF Lending," World Politics, Vol. 52 (October), pp. 38-75.

Train, Kenneth, 2003, Discrete Choice Methods with Simulation (Cambridge, United Kingdom, Cambridge University Press).

Trudel, Robert, 2005, "Effects of Exchange Rate Regime on IMF Program Participation," Review of Policy Research, Vol. 22 (November), pp. 919-36.

Vreeland, James, 2004, "Institutional Determinants of IMF Agreements," Global Fellows Working Paper (Los Angeles, UCLA International Institute). Available via the Internet: repositories.cdlib.org/cgi/viewcontent.cgi?article $=1004 \&$ context $=$ international.

Windmeijer, Frank, 1995, "Goodness-of-Fit Measures in Binary Choice Models," Econometric Reviews, Vol. 14, No. 1, pp. 101-16. 